\title{
Theoretical Studies on the Transport Mechanism of 5-Fluorouracil through Cyclic Peptide Based Nanotubes
}

\author{
Ramadoss Vijayaraj, ${ }^{\dagger}$ Sofie Van Damme, ${ }^{*}$ Patrick Bultinck, ${ }^{\star}$ and Venkatesan Subramanian ${ }^{\dagger *}$ \\ Chemical Laboratory, CSIR-Central Leather Research Institute, Adyar, Chennai 600 020, India and \\ Department of Inorganic and Physical Chemistry, Ghent University, Krijgslaan 281(S3), Gent 9000, \\ Belgium
}

\begin{abstract}
Cyclic peptide nanotubes (CPNTs) formed by the self-assembly of cyclic peptides (CPs) with an even number of alternate L/D amino acids are typically used in the field of the transport of ions and drug molecules across the lipid bilayer. This study investigates the transport mechanism of the antitumor drug molecule, 5-Fluorouracil (5FU), through the CPNT using classical and steered molecular dynamics simulations combined with umbrella sampling. During the transport of 5FU through the CPNT, 5FU is partially desolvated because the lumen of the CPNT is too small to allow for water molecules solvating it. 5FU forms $\mathrm{H}$ bonding interactions with the backbones of CPNT and at the same time, also forms hydrophobic contacts with the backbone $\mathrm{C} \alpha$ and $\mathrm{C}$ atoms of CPNT. The cooperative breaking of the H-bond and hydrophobic interactions between CPNT and 5FU increases the pulling force to transport the 5FU from the mid-C $\alpha$ region to the $\mathrm{C} \alpha$ one. The calculated free energies of binding reveal that the energy barriers for the transport of 5FU are $\sim-6.0$ and $\sim-2.0$ $\mathrm{kcal} / \mathrm{mol}$ in the mid-C $\alpha$ and $\mathrm{C} \alpha$ plane regions, respectively.
\end{abstract}

Keywords: Self-assembly, Drug delivery, Hydrogen bond, Molecular dynamics, Umbrella sampling, Transport mechanism.

\footnotetext{
*To whom correspondence should be addressed. E-mail: subuchem@hotmail.com ${ }^{\dagger}$ Central Leather Research Institute.

Ghent University.
} 


\section{Introduction}

Since the discovery of the capability of cyclic peptide based nanotubes (CPNTs) to diffuse into lipid bilayers, ${ }^{1-3}$ several studies have been conducted to unravel the energetics and transport mechanism of various ions and drug molecules through CPNTs. ${ }^{4-10}$ It has been demonstrated using experimental and theoretical studies that a CPNT embedded in a lipid bilayer can act as an active transporter for various molecules. ${ }^{4-8,11-13}$ Granja et al. showed that the synthetic decapeptide $c y c l o\left[(\operatorname{Trp}-\mathrm{D}-\mathrm{Leu})_{4}\right.$-Gln-D-Leu] can, upon self-assembly, transport glucose. ${ }^{4}$ Recently, it has been shown that the antitumor activity of 5-Fluorouracil (5FU) is enhanced in the presence of CPNTs. ${ }^{11}$ The diffusion of 5FU from liposomes is increased from $5 \%$ in the absence of CPNTs to $70 \%$ in its presence. ${ }^{11}$ This observation warrants a more in-depth study of the transport phenomenon.

A crucial aspect of such a study is the structural characterization of CPNTs. Cyclic peptides (CPs) with alternating L/D chirality of the composing amino acids can self-assemble by forming hydrogen bonds (H-bonds) between the carbonyl-amide functionality of subsequent CP units. ${ }^{14-16}$ The intermolecular H-bonding between the CPs forms a $\beta$-sheet like structure due to the antiparallel stacking of CPs. In addition to the intermolecular H-bonding, the self-assembled CPNT is further stabilized by various interactions among the side chains. The backbone carbonyl-amide groups orient along the tube axis and the amino acid side chains protrude from the surface of the tube. Thus, the lumen of the tube is free from side chains of the amino acids, hence facilitating the transport of various molecules through the CPNT. The internal diameter of the CPNT is a distinct property of the number of amino acids in the $\mathrm{CP} .{ }^{17,18}$

The structures, stabilities and water transport properties of different CPNTs have been the subject of various experimental and theoretical studies. ${ }^{9,16,19-26}$ The structure of the CPNT 
is characterized as the alternating $\mathrm{C} \alpha$ and mid-C $\alpha$ regions. The plane formed by the $\mathrm{C} \alpha$ atoms in a CP is called the $\mathrm{C} \alpha$ plane. The region in between two $\mathrm{C} \alpha$ planes is referred to as the mid$\mathrm{C} \alpha$ region. The water molecule arrangement in CPNT formed by octa-cyclic-peptides was found to consist of one and two water molecules in the backbone $\mathrm{C} \alpha$ plane and mid-C $\alpha$ plane regions, respectively. ${ }^{12,27-29}$ The lumen of the CPNT confines the number of solvent molecules that can coordinate around a solute diffusing through the CPNT. This has been confirmed in a study where the solute corresponds to a metal ion. ${ }^{6}$ There it was found that the solvation of ions inside the CPNT is considerably different from that in the bulk. Asthagiri et al. have studied the energetics of diffusion of $\mathrm{Li}^{+}, \mathrm{Na}^{+}, \mathrm{Rb}^{+}$and $\mathrm{Cl}^{-}$ions inside the CPNT using an MD simulation based perturbation free energy method. ${ }^{6}$ The potential of mean force (PMF) for the diffusion of $\mathrm{Na}^{+}$and $\mathrm{K}^{+}$ions through the $\left\{(\mathrm{D}-\mathrm{Ala}-\mathrm{Glu}-\mathrm{D}-\mathrm{Ala}-\mathrm{Gln})_{2}\right\}_{4}$ nanotube in aqueous medium has been analyzed using steered molecular dynamics (SMD) simulations. ${ }^{9}$ Given the facts that these methods allowed obtaining better insight in effects governing the transport of solutes through CPNT, our study uses the same methodology.

The transport mechanism of 5FU through the CPNT consisting of the cyclo[(Trp-DLeu $)_{4}$-Gln-D-Leu] $\}_{8}$ peptide embedded in the hydrated dimyristoylphosphatidylcholine (DMPC) lipid bilayer has previously been studied using SMD simulation. ${ }^{11}$ However, the free energy related to the transport of 5FU through the CPNT has not been scrutinized. Given the importance of $5 \mathrm{FU}$ as a drug and the previously observed enhanced diffusion of $5 \mathrm{FU}$ from liposomes in the presence of CPNT, ${ }^{11}$ this study is aimed at elucidating the mechanism of this transport. In the present study, SMD and umbrella sampling (US) simulations were carried out to explore the free energy for the transport of 5FU through CPNT. Emphasis has been placed on the different interactions between CPNTs and 5FU in the transport pathway. As a consequence, it is possible to define the transport mechanism as that set of interactions and 
their changes that accompany the movement of the drug substance through the CPNT. The results obtained add a new dimension to the understanding of this mechanism by studying the following aspects (a) the transport mechanism of 5FU through the CPNTs, (b) the free energy barrier for the transport of 5FU through CPNTs, and (c) the role of the structure and stability of the CPNTs in the transport of 5FU.

\section{Computational details}

\section{Classical Molecular Dynamics}

The CPNTs consisting of $\left.\left.8\{\text { cyclo-[(D-Trp-L-Leu })_{5}\right]\right\}$ units and 8 \{cyclo-[(L-Ala-DGln-L-Ala-D-Glu)2-L-Ala-D-Gln]\} units were constructed by antiparallel stacking of these CP units. The structures of both model systems are given in Figure S1 of the Supporting Information. In our previous study, we have carried out binding energy calculations on various CPNTs (cyclo-[(D-Ala-L-Ala $\left.)_{4}\right]$, cyclo-[(D-Ala-L-Phe $\left.)_{4}\right]$, cyclo-[(D-Ala-L-Leu $\left.)_{4}\right]$, cyclo-[(D-Ala-L-Gln $\left.)_{4}\right], \quad$ cyclo-[(L-Gln-D-Ala-L-Glu-D-Ala $\left.)_{2}\right], \quad$ cyclo-[(D-Gln-L-Leu $\left.)_{4}\right]$, cyclo-[(D-Trp-L-Leu $\left.)_{4}\right]$, cyclo-[(D-Trp-L-Leu $\left.\left.)_{3}-\mathrm{D}-\mathrm{Gln}-\mathrm{L}-\mathrm{Leu}\right]\right)$ using the MM/PBSA method to unravel the stability of CPNTs composed of different amino acids. ${ }^{30}$ It has been found from the study that the CPNT composed of $\left\{c y c l o\left[(\mathrm{D}-\mathrm{Trp}-\mathrm{L}-\mathrm{Leu})_{4}\right]\right\}_{8}$ is significantly more stable than the other CPNTs. The CPNT with $\left.\left.\{\text { cyclo[(L-Gln-D-Ala-L-Glu-D-Ala })_{2}\right]\right\}_{8}$ is found to be the least stable one. Based on the above findings, $\left\{\text { cyclo- }\left[(\mathrm{D}-\mathrm{Trp}-\mathrm{L}-\mathrm{Leu})_{5}\right]\right\}_{8}$ and $\{$ cyclo- $[(\mathrm{L}-$ Ala-D-Gln-L-Ala-D-Glu) $\left.\left.{ }_{2}-\mathrm{L}-\mathrm{Ala}-\mathrm{D}-\mathrm{Gln}\right]\right\}_{8}$ CPNTs were selected for the present study. The side chains of all Glu residues in the model were protonated to avoid any repulsive electrostatic interaction between the negatively charged carboxylate groups. Each CPNT is inserted in a cubic water box with TIP3P water molecules extending $16 \AA$ away from the solute atoms. ${ }^{31,32}$ All systems were subjected to energy minimization, equilibration and production simulations. The different steps in the simulations are: a) all atom energy 
minimization for 10,000 cycles without any position restraints. b) equilibration of the solvent molecules for 200 ps by restraining the solute atoms through a harmonic force constant of $1000 \mathrm{~kJ} \mathrm{~nm}^{-2}$ in the NVT ensemble, followed by NPT equilibration without any position restraints. c) production MD simulation in the absence of any restraints for $10 \mathrm{~ns}$ in NPT ensemble with a 2 fs time step. All simulations were carried out with periodic boundary conditions applied in three dimensions. The pressure was controlled at 1 atm using a Parrinello-Rahman barostat. ${ }^{33}$ The $\mathrm{CP}$ and non-CP atoms were coupled to separate temperature coupling baths and the temperature was maintained at $300 \mathrm{~K}$ with a velocity rescaling thermostat. ${ }^{34}$ The particle-mesh Ewald (PME) summation method was used for calculating the long-range electrostatic interactions. ${ }^{35}$ The short-range and long-range nonbonded interactions were truncated using a 1.4 and $12.0 \AA$ cutoff, respectively. The linear constraint solver (LINCS) algorithm was used to constrain the bonds involving hydrogen atoms. $^{36}$

\section{Steered Molecular Dynamics and Umbrella sampling}

The final structure obtained from the classical MD simulation was used for the SMD or centre of mass (COM) pulling simulation. The SMD simulation was carried out to pull the 5FU through the lumen of CPNT. The schematic representation of diffusion of 5FU through the CPNT is depicted in Scheme 1. The chemical structure and atomic numbering of 5FU is presented in Figure 1. The force field for 5FU was generated using the Antechamber program of AmberTools $1.5^{37}$ with the general amber force field (GAFF) parameters. ${ }^{38}$ The partial charges of 5FU were calculated using the RESP fitting technique ${ }^{39-41}$ based on the optimized B3LYP/6-31G* structure and electrostatic potential employing the Gaussian 03 suite of programs. $^{42-45}$ 
The complexes of 5FU with $\left.\left.\{\text { cyclo-[(D-Trp-L-Leu })_{5}\right]\right\}_{8}$ and $\{$ cyclo-[(L-Ala-D-Gln-LAla-D-Glu) ${ }_{2}$-L-Ala-D-Gln] $\}_{8}$ were designated as WL and QAEA, respectively. The 5FU was positioned at $\sim 10 \AA$ away from the centre of mass of the first CP unit of each model. Both models were solvated with TIP3P water molecules with sufficient space in the 5FU pulling direction (henceforth considered to be the direction of the z-axis). The extended solvation of the CPNT on the z-axis enables to position the 5FU in bulk water at the initial and final stages of the pulling simulation. Before pulling, all systems were equilibrated by restraining the CPNT and 5FU for $1 \mathrm{~ns}$ in the NPT ensemble using classical MD simulation, as described in the previous section. During the SMD simulation, the CPNT was considered as the reference group for the pulling of 5FU through the CPNT. A harmonic spring constant of $1000 \mathrm{~kJ} \mathrm{~mol}^{-1} \mathrm{~nm}^{-2}$ and a pulling rate of $0.001 \mathrm{~nm} / \mathrm{ps}$ were used for all SMD simulations. The SMD simulations with different pulling rates $(0.001,0.0025$, and $0.005 \mathrm{~nm} / \mathrm{ps})$ produced similar force profiles. Thus, the $0.001 \mathrm{~nm} / \mathrm{ps}$ pulling rate was used to cover the proper conformational sampling space. In order to allow the experimentally observed tilt in the CPNT structure immersed in a lipid bilayer, ${ }^{1}$ the SMD simulations were performed by restraining the backbone heavy atoms of the first monomer $\mathrm{CP}$ unit. ${ }^{6,10}$

The trajectories obtained from each of the SMD simulations were used to extract 50 frames corresponding to the decreasing (and increasing) COM distance between the reference and pulling group with a step size of $0.1 \mathrm{~nm}$. The extracted frames (umbrella sampling windows) form the reaction coordinate $(\xi)$ for the US simulations. The US simulations on each of the 100 umbrella sampling windows were carried out for 10 ns. The weighted histogram analysis method (WHAM) was used with the cyclic option to extract the free energy of binding ( $\Delta \mathrm{G}_{\text {binding }}$ ) of each system from the US simulations. ${ }^{46}$ The classical/steered 
MD and US simulations were performed using GROMACS 4.5.5 $5^{47,48}$ employing ff99SB ${ }^{49}$ force field parameters.

\section{QM calculations}

The hydrated geometry of 5FU was optimized at the B3LYP/6-31+G* level of theory. ${ }^{42-44}$ The calculated Hessian for the optimized geometry confirmed that the obtained structure is minimum on the potential energy surface. The optimized geometry was used to calculate the 5FU-water dimer interaction energy (IE) for each hydration site $\left(\mathrm{H}_{7}, \mathrm{O}_{8}, \mathrm{H}_{9}\right.$, and $\left.\mathrm{O}_{10}\right)$. The IEs were calculated at the M05-2X/6-31+G* level of theory. ${ }^{50-52}$ The counterpoise (CP) procedure suggested by Boys and Bernardi was used to calculate the basis set superposition error (BSSE) ${ }^{53-56}$ All the calculations were carried out using the Gaussian 03 suite of programs. ${ }^{45}$

\section{Results and discussion}

\section{Transport pathway}

The variation of the pulling force along the z-axis with time for the WL and QAEA system is depicted in Figure 2. When 5FU is transported from the $\mathrm{C} \alpha$ plane to the mid-C $\alpha$ region, the pulling force decreases linearly and reaches local minima. The force then increases again from the mid-C $\alpha$ region to the $\mathrm{C} \alpha$ plane during the transport of 5FU. Thus a nearly periodic oscillatory pattern of force with time can be observed from the profile due to the periodic nature of the CPNT structure. A similar variation of force with time has also been found during the diffusion of 5FU through the CPNT embedded in the DMPC lipid bilayer. ${ }^{11}$ The spatial distribution function, i.e. the three-dimensional (3D) density distribution of all the atoms of 5FU during its transport through the WL and QAEA systems was calculated. The 3D density distribution of 5FU is presented in Figure 3 and also in Supporting 
Information (Figure S2). The flat distribution surface of 5FU during the transport demonstrates that the axis passing through $\mathrm{O}_{8}$ and $\mathrm{F}_{11}$ or $\mathrm{H}_{7}$ and $\mathrm{O}_{10}$ or $\mathrm{H}_{9}$ and $\mathrm{H}_{12}$ of $5 \mathrm{FU}$ is parallel to the axis of CPNT.

\section{Intermolecular interactions}

With the aim of understanding the interactions responsible for the transport of $5 \mathrm{FU}$ through the CPNT, the H-bonding and hydrophobic interactions in the entire system $(\mathrm{CPNT}+5 \mathrm{FU}+$ water $(\mathrm{WAT}))$ were analyzed using the trajectories obtained from the SMD simulations.

\section{FU-Water Interactions}

The H-bonds between the different atoms of 5FU and the water molecules observed from the SMD simulations of the WL and QAEA systems are displayed in Figure 4. In this figure, the van der Waals contact domain of 5FU with the backbone atoms of CPNT is shown, illustrating the hydration pattern of $5 \mathrm{FU}$ in the bulk water medium and in the lumen of the CPNT. This shows that the hydration pattern of 5FU is not continuous in the transport pathway. The difference in the hydration profile of $5 \mathrm{FU}$ in the bulk water medium and during the transport may arise due to the following: (i) 5FU is H-bonded with the CPNT and (ii) the density of water molecules is comparatively less in the lumen of the CPNT when compared to the bulk. It is clearly evident from Figure 4 that the H-bonds between $\mathrm{N}_{1} \mathrm{H}_{7}(5 \mathrm{FU}) \cdots \mathrm{O}\left(\right.$ WAT) and $\mathrm{N}_{3} \mathrm{H}_{9}(5 \mathrm{FU}) \cdots \mathrm{O}($ WAT) are disrupted during the transport. Particularly, the $\mathrm{N}_{3} \mathrm{H}_{9}(5 \mathrm{FU}) \cdots \mathrm{O}$ (WAT) H-bond is significantly affected during the transport of 5FU through the CPNT. Hence, partial desolvation of 5FU takes place during the transport. 
In order to explore the density of water molecules around 5FU, the radial distribution function (RDF, $g(r)$ ) corresponding to the interaction of water molecules with various H-bond donor/acceptor atoms in 5FU was calculated. Figure 5 (as well as Figure S3 in Supporting Information) shows the RDF of 5FU in bulk water and during transport. The presence of 5FU in the bulk water as well as in the transport pathway was distinguished from the van der Waals contact between the 5FU and backbone atoms of CPNT as shown in Figure 4. Figures $5 \mathrm{~A}$ and $5 \mathrm{~B}$ show the RDF for the bulk water interactions with the different atoms of 5FU in the WL and QAEA systems. The RDF of the water molecules interacting inside the tube with 5FU is given in Figures 5C and 5D. It can be seen that there is a significant reduction in the $\mathrm{g}(\mathrm{r})$ value during the transport of 5FU through the CPNT. The desolvation of 5FU is clearly evident from the variation of $\mathrm{g}(\mathrm{r})$ with distance. From Figures $5 \mathrm{~A}$ and $5 \mathrm{~B}$, it is possible to account multiple small peaks at $\mathrm{r}<3.5 \AA$ for the $\mathrm{O}_{10} / \mathrm{O}_{8}(5 \mathrm{FU}) \cdots \mathrm{O}($ WAT) H-bond. This feature shows that more than one water molecules interact with the $\mathrm{O}_{10} / \mathrm{O}_{8}$ site due to the dynamical nature of the H-bond interaction in the bulk medium. However, no similar multiple peaks (Figures 5C and 5D) are found for the same sites during the transport of 5FU through the CPNT. This is due to the structural confinement and associated reduction in the water content in the lumen of the tube. These findings are in agreement with the disruptions in the H-bonding pattern for various sites in Figure 4.

The comparison of the RDF plots in Figure 5 reveals that there is a significant reduction in $\mathrm{g}(\mathrm{r})$ of $\mathrm{N}_{3} \mathrm{H}_{9}(5 \mathrm{FU}) \cdots \mathrm{O}(\mathrm{WAT})$ H-bonding compared to the $\mathrm{N}_{1} \mathrm{H}_{7}(5 \mathrm{FU}) \cdots \mathrm{O}$ (WAT) H-bonding during the transport of 5FU. It is clear from Figure 5 that the $\mathrm{F}(5 \mathrm{FU}) \cdots \mathrm{O}($ WAT) interaction appears at $\sim 3.2 \AA$. On the other hand, the interaction between $\mathrm{F}(5 \mathrm{FU}) \cdots \mathrm{H}(\mathrm{WAT})$ does not show any appreciable peak at distances $<2 \AA$ (Figure S3 in Supporting Information). Therefore, the density of water molecules around the F atom 
of $5 \mathrm{FU}$ is less than that of other sites. In fact, the $\mathrm{F}(5 \mathrm{FU}) \cdots \mathrm{O}($ WAT) H-bond exists only for $13 \%$ of the total 6000 frames analyzed. Previous MD simulations of 5FU molecules in aqueous solution revealed a similar kind of RDF pattern for the $\mathrm{F}(5 \mathrm{FU}) \cdots \mathrm{O}(\mathrm{WAT}) \mathrm{H}$-bond. ${ }^{57}$ Glusker et al. have first proposed the C-F $\cdots \mathrm{H}-\mathrm{O}$ type of $\mathrm{H}$-bonds in $1983 .^{58}$ Further studies on such H-bonding systems confirmed that their interaction is weak and is rarely found in the Cambridge Structural Database System (CSDS) with dispersed F $\cdots \mathrm{H}-\mathrm{X}$ angles. ${ }^{59-69}$ Overall, these findings show that both desolvation of 5FU and reduced water content in the lumen of the CPNT facilitate the transport of 5FU through CPNT.

\section{CPNT-Water Interactions}

Several experimental and theoretical studies have been carried out to understand the hydration of the backbone carbonyl-amide groups of CPNT and the diffusion of water through the CPNT. ${ }^{11-13,27,70}$ The earlier MD study shows that the tendency for the backbone amide group to interact with water molecules is relatively small. ${ }^{27}$ On the other hand, the carbonyl group clearly interact in a significant manner with the water molecules. Figure 6 shows the RDF corresponding to the interaction of the $\mathrm{O}$ atom of water molecules with different carbonyl-amide groups of the CPNTs. The occurrence of a sharp peak at $2.78 \AA$ corresponds to the $\mathrm{O}(\mathrm{CPNT}) \cdots \mathrm{O}($ WAT $)$ interaction. It can be noted that this distance is closer to the donor-acceptor distance in the classical H-bonded systems.

The running average (from the SMD simulation) of the number of H-bonds between water molecules and carbonyl $\mathrm{O}$ atoms of the CP's for various model systems are given in Figure S4 of Supporting Information. The plot of the average number of H-bonds with time also reveals the position of 5FU during the transport. During the transport, the number of carbonyl $\mathrm{O}(\mathrm{CPNT}) \cdots \mathrm{O}($ WAT $) \mathrm{H}$-bonds decreases i.e. water molecules get displaced by the 5FU molecule. Therefore, the disruption in the carbonyl $\mathrm{O}(\mathrm{CPNT}) \cdots \mathrm{O}(\mathrm{WAT}) \mathrm{H}$-bond 
favours the movement of 5FU through the CPNT. The H-bonding interaction between $\mathrm{N}-$ $\mathrm{H}(\mathrm{CPNT}) \cdots \mathrm{O}($ WAT $)$ is observed at $2.10 \AA$. The variation of RDF for $\mathrm{N}(\mathrm{CPNT}) \cdots \mathrm{O}($ WAT $)$ does not exhibit any characteristic peak corresponding to the interactions of amide $\mathrm{N}$ with water molecules. Thus, there is no specific interaction between the amide $\mathrm{N}$ atom, CPNT and water molecules.

\section{CPNT-5FU H-bonds}

The number of H-bonds formed between CPNT and 5FU in the transport pathway was analyzed from the SMD simulation and the results are presented in Figure 7. As evident from the H-bonding between backbone carbonyl-amide and water molecules, the backbone amide group forms a marginally smaller number of $\mathrm{H}$-bonds with 5FU. In agreement with the interrupted $\mathrm{H}$-bonding between the $\mathrm{N}_{3} \mathrm{H}_{9}$ and $\mathrm{N}_{1} \mathrm{H}_{7}$ sites of $5 \mathrm{FU}$ on one hand and the water molecules on the other in the transport pathway, there is an appreciable number of $\mathrm{H}$-bonds observed between carbonyl $\mathrm{O}(\mathrm{CPNT}){ }^{\cdots} \mathrm{N}_{3} \mathrm{H}_{9} / \mathrm{N}_{1} \mathrm{H}_{7}(5 \mathrm{FU})$. The decrease in the carbonyl $\mathrm{O}(\mathrm{CPNT}) \cdots \mathrm{O}$ (WAT) H-bonding interaction suggests that the $\mathrm{N}_{3} \mathrm{H}_{9}$ and $\mathrm{N}_{1} \mathrm{H}_{7}$ groups of $5 \mathrm{FU}$ compete with the water molecules in the formation of CPNT-5FU H-bonding. It is evident from Figure 7 that the frequency of the carbonyl $\mathrm{O}(\mathrm{CPNT}){ }^{\cdots} \mathrm{N}_{3} \mathrm{H}_{9}(5 \mathrm{FU}) \mathrm{H}$-bond (type A) is significantly higher than that of the carbonyl $\mathrm{O}(\mathrm{CPNT}){ }^{\cdots} \mathrm{N}_{1} \mathrm{H}_{7}(5 \mathrm{FU}) \mathrm{H}$-bond (type B). The RDF of the $\mathrm{H}_{7} / \mathrm{H}_{9}(5 \mathrm{FU})$ interactions with backbone carbonyl $\mathrm{O}(\mathrm{CPNT})$ atoms is presented in Figure 8. The observed lower $\mathrm{g}(\mathrm{r})$ values for carbonyl $\mathrm{O}(\mathrm{CPNT}){ }^{\cdots} \mathrm{H}_{7}(5 \mathrm{FU})$ corresponds to the reduced frequency of occurrence of type B H-bonding. In spite of this fact, peaks of $\mathrm{H}_{7} / \mathrm{H}_{9}(5 \mathrm{FU}) \cdots \mathrm{O}\left(\right.$ WAT) (Figure 5) and $\mathrm{H}_{7} / \mathrm{H} 9(5 \mathrm{FU}) \cdots \mathrm{O}(\mathrm{CPNT})$ (Figure 8) are observed at $\sim 2$ $\AA$. It indicates that $\mathrm{H}_{7} / \mathrm{H}_{9}(5 \mathrm{FU})$ atoms can approach the $\mathrm{O}(\mathrm{CPNT})$ and $\mathrm{O}(\mathrm{WAT})$ atoms in a similar way. Both A and B types of H-bonding interactions in the WL system as observed from the SMD simulation are presented in Figure 9. The higher frequency for the type A H- 
bonding interaction suggests the following: (a) the type A H-bond is energetically more stable than type B H-bond, (b) the type A H-bonded CPNT-5FU complex is further stabilized by the water mediated $\mathrm{H}$-bonds formed between $\mathrm{N}_{1} \mathrm{H}_{7}(5 \mathrm{FU}), \mathrm{O}_{8}(5 \mathrm{FU}), \mathrm{O}_{10}(5 \mathrm{FU})$ and $\mathrm{O}(\mathrm{CPNT})$, and (c) the hydrophobic interaction between CPNT and 5FU strengthens the type A H-bonds. However, there is no evidence for the overriding preference for the type A or type B H-bond at the $\mathrm{C} \alpha$ or mid-C $\alpha$ plane regions.

\section{MM/PBSA Interaction Energy}

In order to estimate the stabilities of type A and B H-bonds, the free energy of binding $\left(\Delta \mathrm{G}_{\text {binding }}\right.$ ) between CPNT and 5FU was calculated for all types (A and B) of H-bonded complex structures of the WL and QAEA systems as extracted from the SMD simulations. $\Delta \mathrm{G}_{\text {binding }}$ was calculated using the MM/PBSA method as implemented in Amber Tools 1.5. ${ }^{37}$ The protocols for the MM/PBSA calculation were used as mentioned in our previous study. ${ }^{26}$ However, the conformational entropy was not included due to the wide sampling space. The van der Waals $\left(\Delta \mathrm{E}_{\mathrm{vdW}}\right)$ and electrostatic $\left(\Delta \mathrm{E}_{\text {ele }}\right)$ contributions to $\Delta \mathrm{G}_{\text {binding }}$ are presented in Figures 10 and 11 , respectively. The calculated $\Delta \mathrm{G}_{\text {binding }}$ for the CPNT-5FU complex is depicted in Figure 12. The fluctuation of the $\Delta \mathrm{E}_{\mathrm{vdW}}$ contribution is considerably lower than that of $\Delta \mathrm{E}_{\text {ele. }}$ It can be noted that the repulsive interaction between the polar atoms of CPNT and $5 \mathrm{FU}$ is responsible for the higher fluctuations in the $\Delta \mathrm{G}_{\text {ele. }}$ Thus, the variation in the $\Delta \mathrm{E}_{\text {ele }}$ component is reflected in the calculated $\Delta \mathrm{G}_{\text {binding. It }}$ can be seen that there are no differences in the different energy contributions to $\Delta \mathrm{G}_{\text {binding }}$ for type A and $\mathrm{B} \mathrm{H}$-bonding interactions

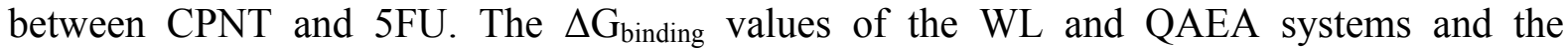
different energy contributions to the $\Delta \mathrm{G}_{\text {binding }}$ for the CPNT-5FU complexes in the absence of type A and B H-bonding are presented in Figures S5 and S6 of Supporting Information, 
respectively. The $\Delta \mathrm{E}_{\text {ele }}$ contribution to the $\Delta \mathrm{G}_{\text {binding }}$ is comparatively less for the non $\mathrm{H}$ bonded complexes when compared to that of type A and B H-bonded complexes.

\section{Water Bridges between CPNT and 5FU}

Figure 13 shows the water mediated H-bond between $\mathrm{O}(\mathrm{CPNT})$ and various atoms of 5FU as observed from SMD simulations of the WL and QAEA systems. The bridges between the CPNT and 5FU through water molecules are displayed in Figure 9. In agreement with the predominant occurrence of type A H-bonds, the $\mathrm{O}(\mathrm{CPNT}){ }^{\cdots} \mathrm{H}-\mathrm{O}(\mathrm{WAT}){ }^{\cdots} \mathrm{N}_{3} \mathrm{H}_{9}(5 \mathrm{FU}) \mathrm{H}-$ bonds exhibit more disruptions than the $\mathrm{O}(\mathrm{CPNT}){ }^{\cdots} \mathrm{H}-\mathrm{O}($ WAT $){ }^{\cdots} \mathrm{N}_{1} \mathrm{H}_{7}(5 \mathrm{FU}) \mathrm{H}-$ bonds. The RDF of $\mathrm{O}\left(\right.$ WAT) and $\mathrm{H}_{7} / \mathrm{H}_{9}(5 \mathrm{FU})$ atoms were calculated only for the type A and $\mathrm{B} \mathrm{H}-$ bonded complexes. It is evident from the RDF that for the WL system, the water density around the $\mathrm{H}_{9}(5 \mathrm{FU})$ atom is comparatively lower than that of $\mathrm{H}_{7}(5 \mathrm{FU})$ (Figure S7a of Supporting Information). However, the same density values for the QAEA system do not show such variations (Figure S7b of Supporting Information). Overall the results show that the type A H-bonded complex facilitates water mediated H-bonds between CPNT and $\mathrm{N}_{1} \mathrm{H}_{7}(5 \mathrm{FU})$. Thus type A H-bonding is highly favoured over type B H-bonding. The amide group of $\mathrm{CP}$ also forms marginal water mediated $\mathrm{H}$-bonds with various atoms of 5FU (Figures S8 and S9 in Supporting Information). The water mediated amide $\mathrm{N}-$ $\mathrm{H}(\mathrm{CPNT}) \cdots 5 \mathrm{FU}$ H-bond occurs comparatively less frequently than carbonyl O(CPNT)-5FU H-bonds.

\section{FU-water interaction energy}

The optimized structure of the 5FU-water complex along with the hydrogen bonding distances is displayed in Figure 14. In order to assess the propensity of various sites in the 5FU for H-bonding interaction with water molecules, the interaction energy of each water 
molecule with $5 \mathrm{FU}$ was calculated by deleting the coordinates of the other three water molecules. The counterpoise corrected IE calculated using M05-2X/6-31+G* is presented in Table 1. The trend in the interaction energy is: $\operatorname{IE}\left(\mathrm{N}_{1} \mathrm{H}_{7}(5 \mathrm{FU}) \cdots\right.$ WAT4 $)<$ $\operatorname{IE}\left(\mathrm{N}_{3} \mathrm{H}_{9}(5 \mathrm{FU}) \cdots\right.$ WAT2 $)<\operatorname{IE}\left(\mathrm{O}_{8}(5 \mathrm{FU}) \cdots\right.$ WAT3 $)<\operatorname{IE}\left(\mathrm{O}_{10}(5 \mathrm{FU}) \cdots\right.$ WAT1 $)$. Comparison of $\operatorname{IE}\left(\mathrm{N}_{1} \mathrm{H}_{7}(5 \mathrm{FU}) \cdots\right.$ WAT4) with $\operatorname{IE}\left(\mathrm{N}_{3} \mathrm{H}_{9}(5 \mathrm{FU}) \cdots\right.$ WAT2) reveals that the water molecule interacts more strongly with the $\mathrm{N}_{1} \mathrm{H}_{7}$ site than the $\mathrm{N}_{3} \mathrm{H}_{9}$ site. This finding holds good agreement with the molecular dynamics information on the tendency of desolvation (the tendency of desolvation at the $\mathrm{N}_{1} \mathrm{H}_{7}$ site is smaller than that of the $\mathrm{N}_{3} \mathrm{H}_{9}$ site) during the transport of 5FU.

\section{Hydrophobic interactions}

The interactions between the $\mathrm{C} \alpha$ and $\mathrm{C}$ atoms of the CPNT and the $\mathrm{C}_{2}, \mathrm{C}_{4}, \mathrm{C}_{5}, \mathrm{C}_{6}$ atoms of 5FU were studied. The inter-atomic cut off distance for hydrophobic interaction was set to $3.5 \AA$. Figure 15 shows the occurrence of such interactions between the CPNT and 5FU in the transport pathway. Figure 16 illustrates the coexistence profile of hydrophobic interactions with $\mathrm{O}(\mathrm{CPNT}){ }^{\cdots} \mathrm{N}_{1} \mathrm{H}_{7} / \mathrm{N}_{3} \mathrm{H}_{9}(5 \mathrm{FU}) \mathrm{H}$-bonds. It is evident from Figure 15 that the hydrophobic interactions between 5FU and CPNT have no preference for type A or B Hbonds. It can be seen from Figure 16 that the hydrophobic and H-bond interactions facilitate the transport of 5FU. This suggests that 5FU interacts with $\mathrm{C} \alpha$ and mid $\mathrm{C} \alpha$ regions simultaneously. For the transport of 5FU through the successive $\mathrm{C} \alpha$ planes, a significant amount of force is required to break these interactions. Thus the force reaches its maximum value during the transport of $5 \mathrm{FU}$ in the $\mathrm{C} \alpha$ plane.

\section{Free energy of binding}


The PMF curves obtained from the US simulations corresponding to the transport of 5FU through the WL and QAEA systems are given in Figure 17. There is a clear periodicity in the PMF as a function of the position of 5FU in the CPNT. The free energy of binding reaches maximum values of $\sim-6.0 \mathrm{kcal} / \mathrm{mol}$ at the mid-C $\alpha$ regions. In the $\mathrm{C} \alpha$ plane, the free energy of binding is $\sim-1.0 \mathrm{kcal} / \mathrm{mol}$. Both hydrophobic and $\mathrm{H}$-bonding interactions between the two systems in the mid-C $\alpha$ region contribute to the maximum free energy of binding of 5FU at the mid-C $\alpha$ region. The energy difference between the $\mathrm{C} \alpha$ and mid-C $\alpha$ regions is in agreement with the energy required to break a single H-bond with additional hydrophobic interaction. The energy barrier for the diffusion of the $\mathrm{Na}^{+}$ion through the CPNT is estimated as $2.0 \mathrm{kcal} / \mathrm{mol}^{10}$ In a different study, the desolvation energy barrier for the $\mathrm{K}^{+}$and $\mathrm{Na}^{+}$to enter the CPNT is predicted as $\sim 2.3$ and $\sim 2.4 \mathrm{kcal} / \mathrm{mol}$, respectively. ${ }^{9}$ From the same study, the free energy well for the transport of the $\mathrm{Na}^{+}$ion is observed as $-4.1 \mathrm{kcal} / \mathrm{mol}$. The observed free energy for the transport of various ions through the CPNT is $\sim 2.0 \mathrm{kcal} / \mathrm{mol}$ less than that of 5FU transport.

\section{Conclusion}

In this study, the transport mechanism of 5-fluorouracil (5FU) through various cyclic peptide nanotubes (CPNTs) was explored using Steered Molecular Dynamics and Umbrella Sampling techniques. The free energy of binding of 5FU with CPNTs in the transport process was calculated from PMF. The transport was simulated by sliding of 5FU in such a way that the principal molecular axis of 5FU is perpendicular to the axis of the CPNT. Various intermolecular interactions between the CPNT, 5FU, and water show that the transport of 5FU is mediated by both direct H-bonding and hydrophobic interactions between CPNT and 5FU. In addition to the direct interactions, water mediated interactions have also been observed. The solvation of $5 \mathrm{FU}$ is significantly reduced in the transport pathway and the 
movement of 5FU occurs by consecutive formation and breaking of new H-bonds with CPNT. During transport, the desolvation of 5FU is not uniform at all sites. The $\mathrm{N}_{3} \mathrm{H}_{9}$ site of 5FU exhibits higher desolvation. The $\mathrm{N}_{3} \mathrm{H}_{9}$ and $\mathrm{N}_{1} \mathrm{H}_{7}$ groups of 5FU form type A and $\mathrm{B} \mathrm{H}-$ bonds with the CPNT. In agreement with the higher desolvation of the $\mathrm{N}_{3} \mathrm{H}_{9}(5 \mathrm{FU})$ site during transport, the type A H-bond is prevalent over type B H-bonds. The MM/PBSA based free energy of binding does not provide any direct evidence for the prevailing type A H-bonding. The quantum mechanical study of the hydration of $5 \mathrm{FU}$ reveals that the $\mathrm{N}_{1} \mathrm{H}_{7}(5 \mathrm{FU}) \cdots$ WAT H-bond is more stable than the $\mathrm{N}_{3} \mathrm{H}_{9}(5 \mathrm{FU}) \cdots$ WAT H-bond. Hence, the desolvation at $\mathrm{N}_{1} \mathrm{H}_{7}(5 \mathrm{FU})$ site is comparatively weaker than the $\mathrm{N}_{3} \mathrm{H}_{9}(5 \mathrm{FU})$ site. This provides direct evidence for the highly preferred type A H-bond between CPNT and 5FU. The $\mathrm{O}_{8} / \mathrm{O}_{9}$ atom of 5FU is involved in the water mediated H-bond between CPNT and 5FU. The 5FU spans the mid- $\mathrm{C} \alpha$ and $\mathrm{C} \alpha$ regions by concurrent formation of $\mathrm{H}$-bond and hydrophobic interactions with the CPNT. Therefore, the pulling force increases at this position to transport 5FU to successive $\mathrm{C} \alpha$ plane regions. The energy barrier for the transport of 5FU from mid-C $\alpha$ region to the $\mathrm{C} \alpha$ plane is $\sim 4.0 \mathrm{kcal} / \mathrm{mol}$.

Results obtained for the transport of 5FU through $\left.\left.\{\text { cyclo-[(D-Trp-L-Leu })_{5}\right]\right\}_{8}(\mathrm{WL})$ are highly comparable with that of 5FU transport through the \{cyclo-[(L-Ala-D-Gln-L-AlaD-Glu) $)_{2}$-L-Ala-D-Gln] $\}_{8}$ (QAEA) system. Among various CPNTs investigated using different experimental and theoretical techniques, the study of one highly stable CPNT and one least stable CPNT reveals no direct relationship between the stability of CPNT and the energy barrier for the transport of small molecule. 


\section{Acknowledgements.}

We thank the Council of Scientific and Industrial Research (CSIR), New Delhi, for financial assistance. One of the authors (R.V.) is grateful to the Erasmus Mundus External Cooperation Window Lot 13, Eurindia project for financial assistance. R. V. and V. S. Acknowledge the Multi-Scale Simulation and Modeling project (MSM) for providing financial assistance. The computational resources (STEVIN Supercomputer Infrastructure) and services used in this work were kindly provided by Ghent University, the Flemish Supercomputer Center (VSC), the Hercules Foundation and the Flemish Government - department EWI.

\section{Electronic Supplementary Information:}

The model structures of the WL and QAEA systems, the spatial distribution function of 5FU in the transport process through the WL and QAEA systems, Radial pair distribution functions between various atoms of $5 \mathrm{FU}$ and $\mathrm{H}$ atoms of water in the WL and QAEA systems. The running average of the number of $\mathrm{H}$-bonds between the water molecules and backbone carbonyl $\mathrm{O}$ atoms of various CPs from the WL and QAEA systems as observed from the SMD simulation. MM/PBSA based various energy contributions to the $\Delta \mathrm{G}_{\text {binding }}$ of non-H-bonded CPNT-5FU complexes extracted from the SMD simulation, Radial distribution function of water $\mathrm{O}$ around $5 \mathrm{FU} \mathrm{H}_{7} / \mathrm{H}_{9}$ atoms in the presence of type $\mathrm{A}$ and $\mathrm{B} \mathrm{H}-$ bonds observed from the WL and QAEA systems, various water mediated H-bonds between the CPNT and 5FU. 


\section{References}

1. H. S. Kim, D. Hartgerink, M. R. Ghadiri, J. Am. Chem. Soc. 1998, 120, 4417-4424.

2. M. Tarek, B. Maigret, C. Chipot, Biophys. J. 2003, 85, 2287-2298.

3. A. Khalfa, W. Treptow, B. Maigret, M. Tarek, Chemical Physics 2009, 358, 161-170.

4. J. R. Granja, M. R. Ghadiri, J. Am. Chem. Soc. 1994, 116, 10785-10786.

5. J. Sanchez-Quesada, M. R. Ghadiri, H. Bayley, O. Braha, J. Am. Chem. Soc. 2000, 122, $11757-11766$.

6. D. Asthagiri, D. Bashford, Biophys. J. 2002, 82, 1176-1189.

7. J. Sanchez-Quesada, M. P. Isler, M. R. Ghadiri, J. Am. Chem. Soc. 2002, 124, 1000410005.

8. H. Hwang, G. C. Schatz, M. A. Ratner, J. Phys. Chem. B 2006, 110, 6999-7008.

9. H. Hwang, G. C. Schatz, M. A. Ratner, J. Phys. Chem. B 2006, 110, 26448-26460.

10. F. Dehez, M. Tarek, C. Chipot, J. Phys. Chem. B Lett. 2007, 111, 10633-10635.

11. H. Liu, J. Chen, Q. Shen, W. Fu, W. Wu, Mol. Pharmaceutics 2010, 7, 1985-1994.

12. J. Liu, J. Fan, M. Tang, W. Zhou, J. Phys. Chem. A 2010, 114, 2376-2383.

13. J. Liu, J. Fan, M. Tang, M. Cen, J. Yan, Z. Liu, W. Zhou, J. Phys. Chem. B 2010, 114, $12183-12192$.

14. M. R. Ghadiri, J. R. Granja, R. A. Milligan, D. E. McRee, N. Khazanovich, Nature 1993, 366, 324-327.

15. M. R. Ghadiri, K. Kobayashi, J. R. Granja, R. K. Chadha, D. E. McRee, Angew. Chem. Int. Ed. Engl. 1995, 34, 93-95.

16. J. D. Hartgerink, J. R. Granja, R. A. Milligan, M. R. Ghadiri, J. Am. Chem. Soc. 1996, 118, 43-50.

17. J. Zhu, J. Cheng, Z. Liao, Z. Lai, B. Liu, J. Comput. Aided Mol. Des. 2008, 22, 773781.

18. N. Khazanovich, J. R. Granja, D. E. McRee, R. A. Milligan, M. R. Ghadiri, J. Am. Chem. Soc. 1994, 116, 6011-6012.

19. C. Gailer, M. Feigel, J. Comput. Aided Mol. Des. 1997, 11, 273-277.

20. J. P. Lewis, N. H. Pawley, O. F. Sankey, J. Phys. Chem. B 1997, 101, 10576-10583.

21. R. A. Jishi, R. M. Flores, M. Valderrama, L. Lou, J. Bragin, J. Phys. Chem. A 1998, 102, 9858-9862.

22. G. Chen, S. Su, R. Liu, J. Phys. Chem. B 2002, 106, 1570-1575. 
23. E. Khurana, S. O. Nielsen, B. Ensing, M. L. Klein, J. Phys. Chem. B 2006, 110, 18965-18972.

24. J. Cheng, J. Zhu, B. Liu, Z. Liao, Z. Lai, Mol. Simulat. 2009, 35, 625-630.

25. W. Qu, H. Tan, G. Chen, R. Liu, Int. J. Quantum Chem. 2010, 110, 1648-1659.

26. R. Vijayaraj, S. S. Raman, R. M. Kumar, V. Subramanian, J. Phys. Chem. B 2010, 114, 16574-16583.

27. M. Engels, D. Bashford, M. Ghadiri, R. J. Am. Chem. Soc. 1995, 117, 9151-9158.

28. J. A. Dani, D. G. Levitt, Biophys. J. 1981, 35, 501-502.

29. S. W. Chiu, E. Jakobsson, S. Subramaniam, J. A. McCammon, Biophys. J. 1991, 60, 273-285.

30. R. Vijayaraj, S. V. Damme, P. Bultinck, V. Subramanian, Phys. Chem. Chem. Phys. 2012, DOI: 10.1039/C2CP42030A.

31. W. L. Jorgensen, J. Am. Chem. Soc. 1981, 103, 335-340.

32. W. L. Jorgensen, J. Chandrasekhar, J. D. Madura, R. W. Impey, M. L. Klein, J. Chem. Phys. 1983, 79, 926-935.

33. M. Parrinello, A. Rahman, J. Appl. Phys. 1981, 52, 7182-7190.

34. G. Bussi, D. Donadio, M. Parrinello, J. Chem. Phys. 2007, 126, 14101-14107.

35. T. Darden, D. York, L. Pedersen, J. Chem. Phys. 1995, 103, 8577-8593.

36. B. Hess, H. Bekker, H. J. C. Bendersen, J. G. E. M. Fraaije, J. Comput. Chem. 1997, 18, 1463-1472.

37. D. A. Case, T. A. Darden, III T. E. Cheatham, C. L. Simmerling, J. Wang, R. E. Duke, R. Luo, R. C. Walker, W. Zhang, K. M. Merz, B. Roberts, B. Wang, S. Hayik, A. Roitberg, G. Seabra, I. Kolossvai, K. F. Wong, F. Paesani, J. Vanicek, J. Liu, X. Wu, S. R. Brozell, T. Steinbrecher, H. Gohlke, Q. Cai, X. Ye, J. Wang, M. J. Hsieh, G. Cui, D. R. Roe, D. H. Mathews, M. G. Seetin, C. Sagui, V. Babin, T. Luchko, S. Gusarov, A. Kovalenko, P. A. Kollman. (2010), AMBER 11, University of California, San Francisco.

38. J. Wang, R. M. Wolf, J. W. Caldwell, P. A. Kollman, D. A. Case, J. Comput. Chem. 2004, 25, 1157-1174.

39. C. I. Bayly, P. Cieplak, W. Cornell, P. A. Kollman, J. Chem. Phys. 1993, 97, 1026910280.

40. P. Cieplak, W. D. Cornell, C. Bayly, P. A. Kollman, J. Comput. Chem. 1995, 16, 1357-1377. 
41. T. Fox, P. A. Kollman, J. Phys. Chem. B 1998, 102, 8070-8079.

42. A. D. Becke, Phys. ReV. A: At., Mol., Opt. Phys. 1988, 38, 3098-3100.

43. C. Lee, W. Yang, R. G. Parr, Phys. ReV. B: Condens. Matter 1988, 37, 785-789.

44. P. J. Stephens, F. J. Devlin, C. F. Chabalowski, M. J. Frisch, J. Phys. Chem. 1994, 98, 11623-11627.

45. M. J. Frisch, G. W. Trucks, H. B. Schlegel, G. E. Scuseria, M. A. Robb, J. R. Cheeseman, J. A. Montgomery, T. Vreven, K. N. Kudin, J. C. Burant, J. M. Millam, S. S. Iyengar, J. Tomasi, V. Barone, B. Mennucci, M. Cossi, G. Scalmani, N. Rega, G. A. Petersson, H. Nakatsuji, M. Hada, M. Ehara, K. Toyota, R. Fukuda, J. Hasegawa, M. Ishida, T. Nakajima, Y. Honda, O. Kitao, H. Nakai, M. Klene, X. Li, J. E. Knox, H. P. Hratchian, J. B. Cross, V. Bakken, C. Adamo, J. Jaramillo, R. Gomperts, R. E. Stratmann, O. Yazyev, A. J. Austin, R. Cammi, C. Pomelli, J. W. Ochterski, P. Y. Ayala, K. Morokuma, G. A. Voth, P. Salvador, J. J. Dannenberg, V. G. Zakrzewski, S. Dapprich, A. D. Daniels, M. C. Strain, O. Farkas, D. K. Malick, A. D. Rabuck, K. Raghavachari, J. B. Foresman, J. V. Ortiz, Q. Cui, A. G. Baboul, S. Clifford, J. Cioslowski, B. B. Stefanov, G. Liu, A. Liashenko, P. Piskorz, I. Komaromi, R. L. Martin, D. J. Fox, T. Keith, M. A. Al-Laham, C. Y. Peng, A. Nanayakkara, M. Challacombe, P. M. W. Gill, B. Johnson, W. Chen, M. W. Wong, C. Gonzalez, J. A. Pople, Gaussian 03, revision E.01; Gaussian, Inc.: Wallingford, CT, 2004.

46. S. Kumar, J. M. Rosenberg, D. Bouzida, R. H. Swendsen, P. A. Kollman, J. Comput. Chem. 1992, 13, 1011-1021.

47. B. Hess, C. Kutzner, D. V. D. Spoel, E. Lindahl, J. Chem. Theory Comput. 2008, 4, $435-447$.

48. http://www.gromacs.org/ (Last accessed on $16^{\text {th }}$ October 2012)

49. V. Hornak, R. Abel, A. Okur, B. Strockbine, A. Roitberg, C. Simmerling, Proteins 2006, 65, 712-725.

50. Y. Zhao, N. E. Schultz, D. G. Truhlar, J. Chem. Phys. 2005, 123, 161103-161104.

51. Y. Zaho, N. E. Schultz, D. G. Truhlar, J. Chem. Theory. Comput. 2006, 2, 364-382.

52. Y. Zaho, D. G. Truhlar, Theor. Chem. Acc. 2008, 120, 215-241.

53. Y. Zhao, N. E. Schultz, D. G. Truhlar, J. Chem. Phys. 2005, 123, 161103-161104.

54. Y. Zaho, N. E. Schultz, D. G. Truhlar, J. Chem. Theory. Comput. 2006, 2, 364-382. 
55. Y. Zaho, D. G. Truhlar, Theor. Chem. Acc. 2008, 120, 215-241.

56. S. F. Boys, F. Bernardi, Mol. Phys. 1970, 19, 553-566.

57. S. Hamad, C. Moon, C. R. A. Catlow, A. T. Hulme, S. L. Price, J. Phys. Chem. B 2006, 110, 3323-3329.

58. P. Murray-Rust, W. C. Stallings, C. T. Monti, R. K. Prestone, J. P. Glusker, J. Am. Chem. Soc. 1983, 105, 3206-3214.

59. L. Shimoni, J. P. Glusker, Struct. Chem. 1994, 5, 383-397.

60. J. A. K. Howard, V. J. Hoy, D. O’Hagan, G. T. Smith, Tetrahedron 1996, 52, $12613-$ 12622.

61. A. Fujii, A. Iwasaki, N. Mikami, Chem. Lett. 1997, 26, 1099-1100.

62. J. D. Dunitz, R. Taylor, Chem. Eur. J. 1997, 3, 89-98.

63. S. J. Borwick, J. A. K. Howard, C. W. Lehmann, D. O’Hagan, Acta Crystallogr., Sect. C 1997, 53, 124-126.

64. M. Pham, M. Gdaniec, T. Polonski, J. Org. Chem. 1998, 63, 3731-3734.

65. T. J. Barbarich, C. D. Rithner, S. M. Miller, O. P. Anderson, S. H. Strauss, J. Am. Chem. Soc. 1999, 121, 4280-4281.

66. A. Kova'cs, I. Mascsa'ri, I. Hargittai, J. Phys. Chem. A 1999, 113, 3110-3114.

67. A. D. Headley, S. D. Starnes, J. Comput. Chem. 2000, 21, 426-431.

68. J. E. Monat, R. R. Toczyowski, S. M. Cybulski, J. Phys. Chem. A 2001, 105, 90049013.

69. H. Takemura, M. Kotoku, M. Yasutake, T. Shinmyozu, Eur. J. Org. Chem. 2004, 2004, 2019-2024.

70. R. García-Fandino, J. R. Granja, M. D’Abramo, M. Orozco, J. Am. Chem. Soc. 2009, 131, 15678-15686. 
Table 1: Calculated IE of 5FU-water at the M05-2X/6-31+G* level of theory.

\begin{tabular}{cc}
\hline system & IE (kcal/mol) \\
\hline 5FU-WAT1 & -6.02 \\
5FU-WAT2 & -7.85 \\
5FU-WAT3 & -7.00 \\
5FU-WAT4 & -9.24 \\
\hline
\end{tabular}

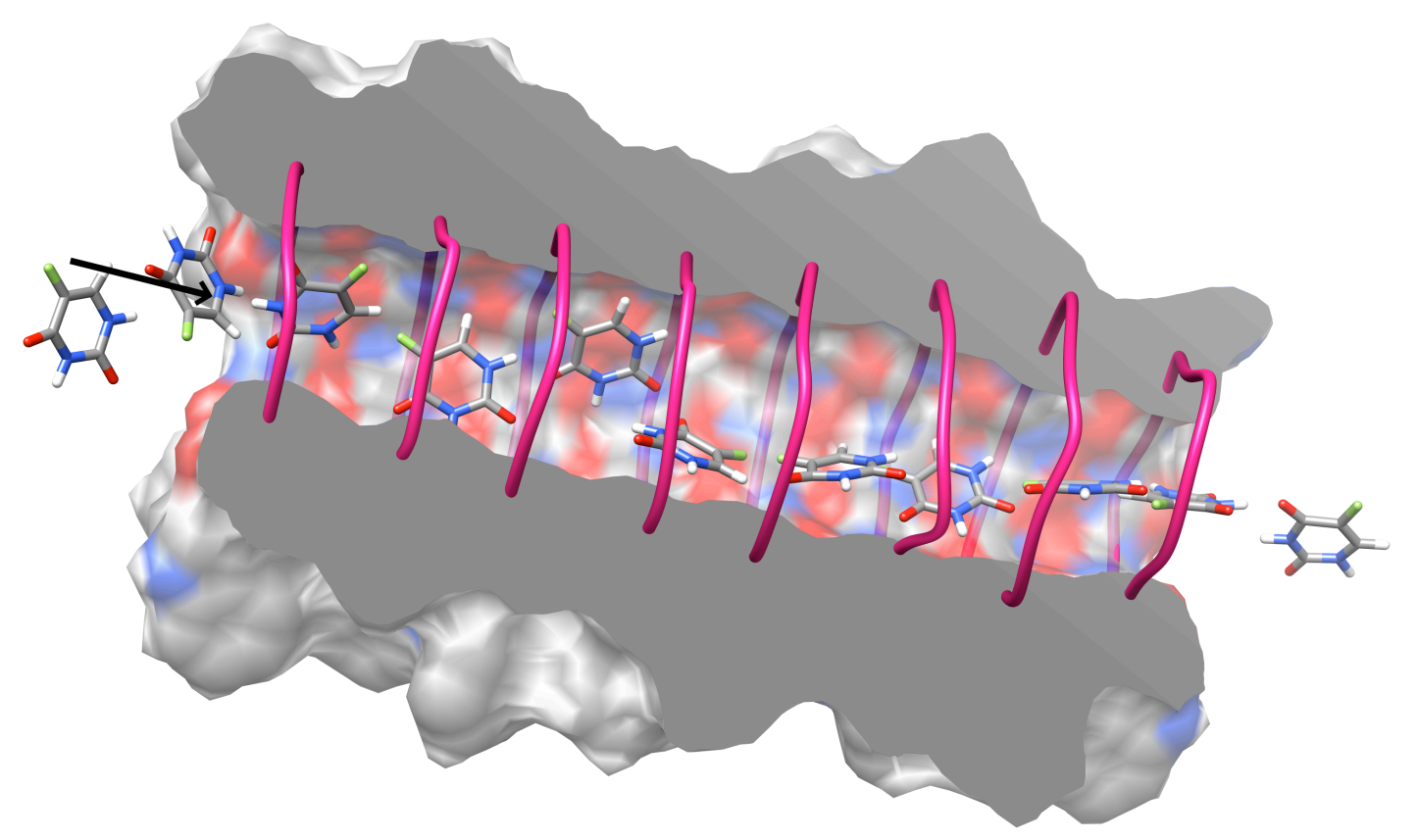

Scheme 1: The model structures of CPNT and 5FU. The direction of transport of 5FU under the external force is shown with an arrow. The solvent accessible surface of the CPNT is sliced to show the transport pathway and the cyclic peptides in the sliced region are represented as ribbons. 
<smiles>Cn1cc(C(F)F)c(=O)[nH]c1=O</smiles>

Figure 1: Chemical structure of 5-Fluorouracil with atom numbering.

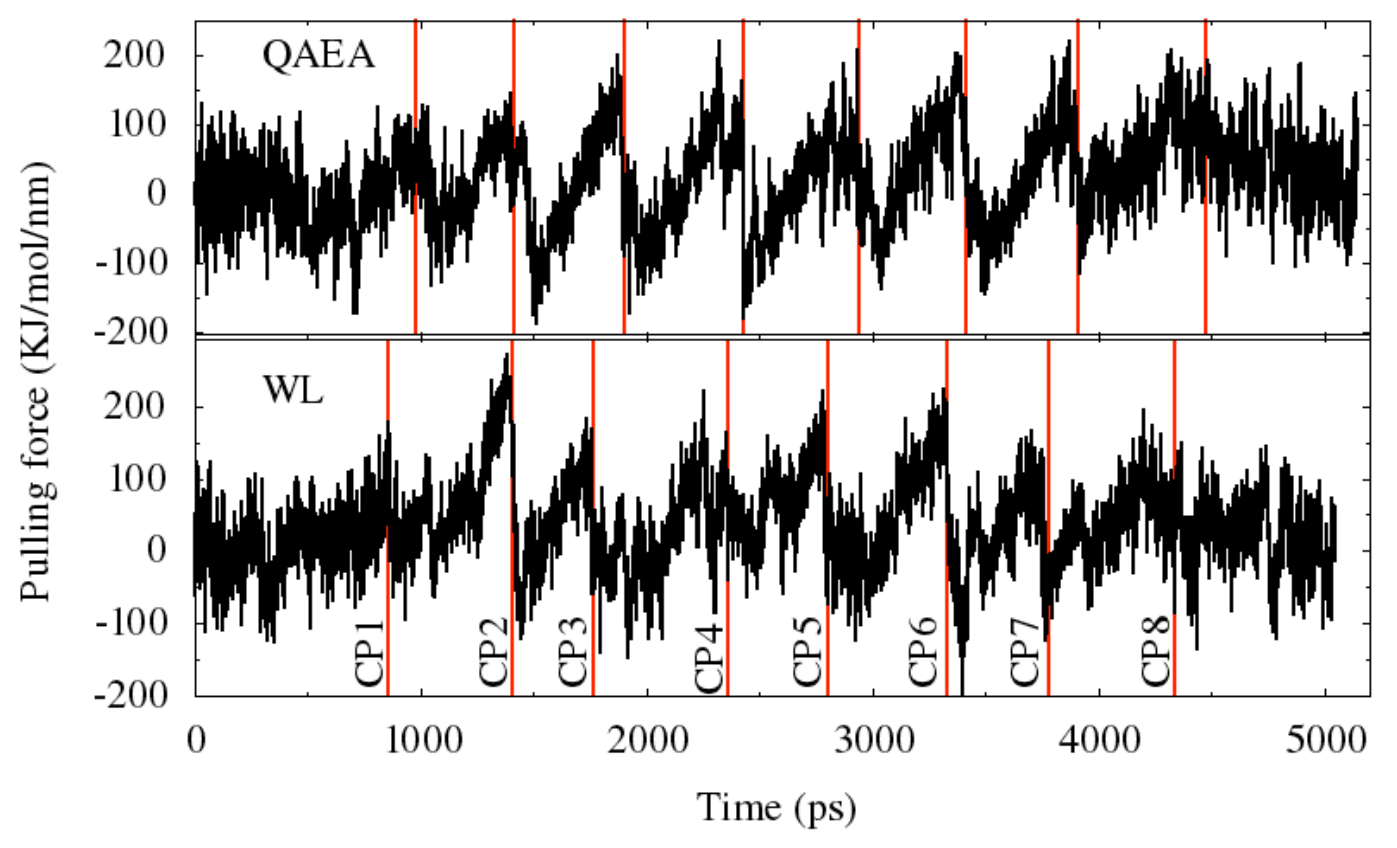

Figure 2: Pulling force (along the $\mathrm{z}$ axis) vs. time plot of the WL and QAEA systems. The vertical red lines represent the mean position of $5 \mathrm{FU}$ corresponding to the $\mathrm{C} \alpha$ plane region of different $\mathrm{CP}$ units. 


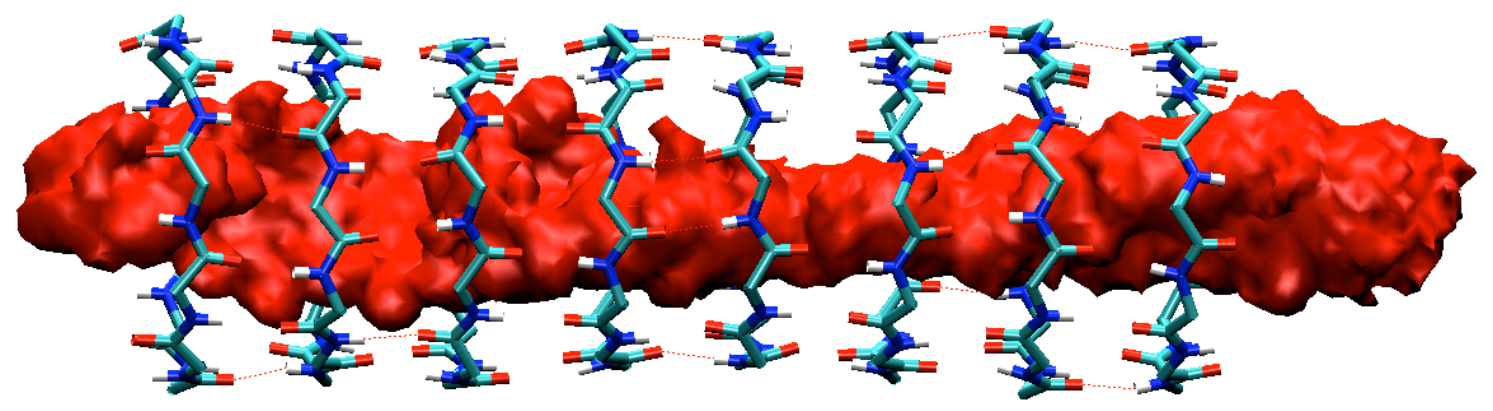

Figure 3: The spatial distribution function of 5FU during its transport through the WL system. The amino acid side chains are not shown for clarity. Intermolecular H-bonding is represented as dotted lines. 
(A)

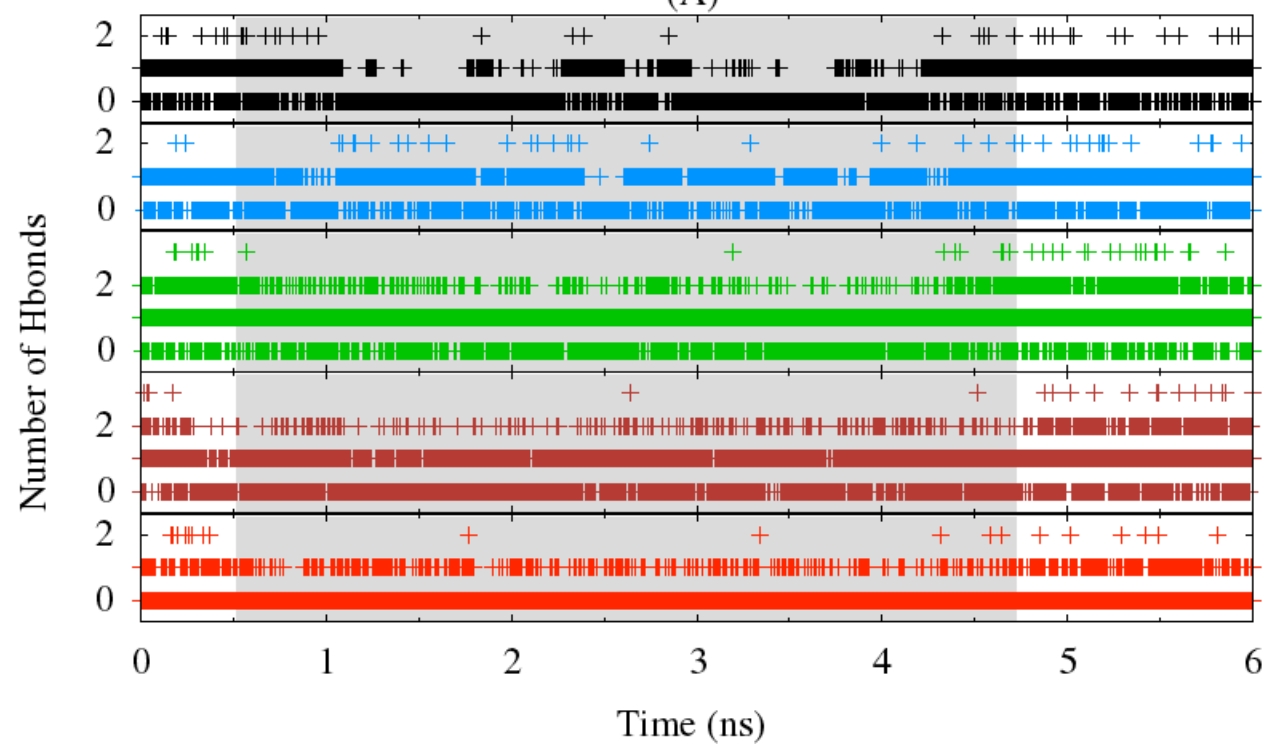

(B)

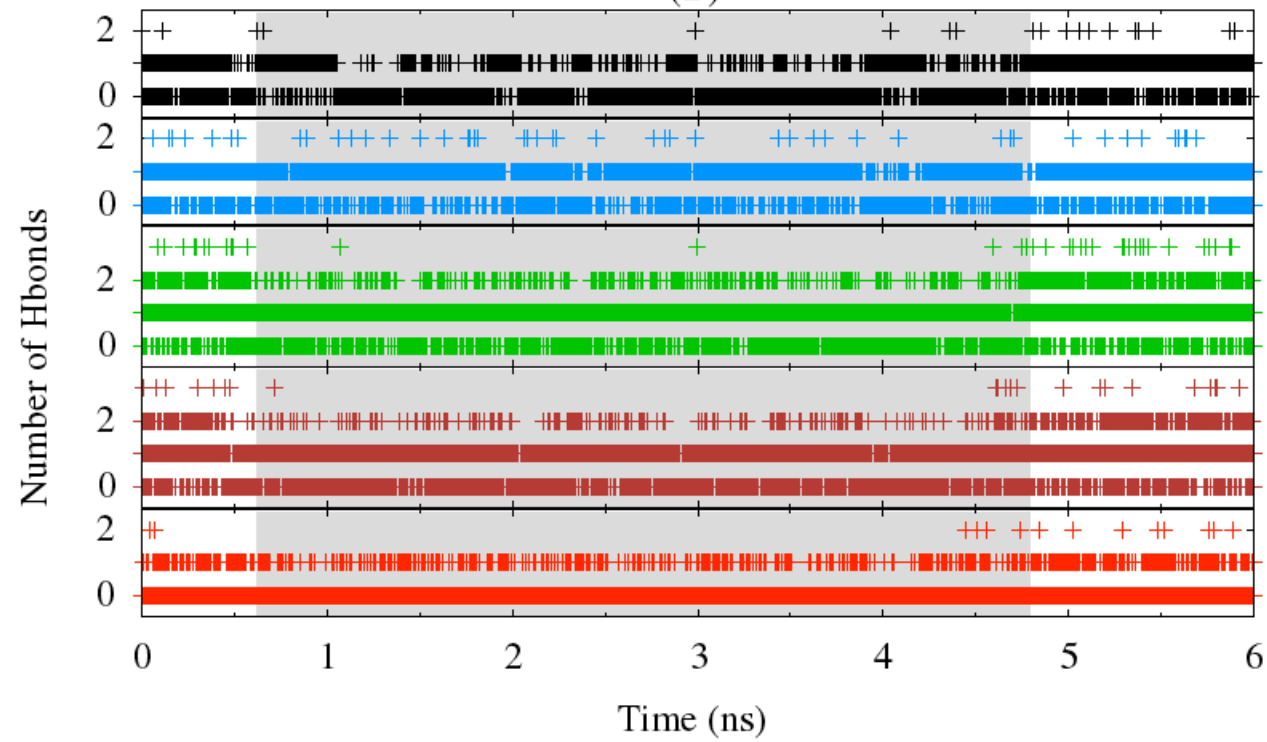

Figure 4: Number of H-bonds observed between the different atoms of 5FU and water molecules from the SMD simulation of the WL (A) and QAEA (B) systems. H-bonds: $\mathrm{N}_{3} \mathrm{H}_{9}(5 \mathrm{FU}) \cdots \mathrm{O}\left(\right.$ WAT) (black), $\mathrm{N}_{1} \mathrm{H}_{7}(5 \mathrm{FU}) \cdots \mathrm{O}\left(\right.$ WAT) (blue), $\mathrm{O}_{10}(5 \mathrm{FU}) \cdots \mathrm{H}(\mathrm{WAT})$ (green) and $\mathrm{O}_{8}(5 \mathrm{FU}) \cdots \mathrm{H}(\mathrm{WAT})$ (brown), $\mathrm{F}_{11}(5 \mathrm{FU}) \cdots \mathrm{H}(\mathrm{WAT})$ (red). The gray coloured background represents the van der Waals contact domain of 5FU $(<3.5 \AA)$ with the backbone atoms of CPNT. 

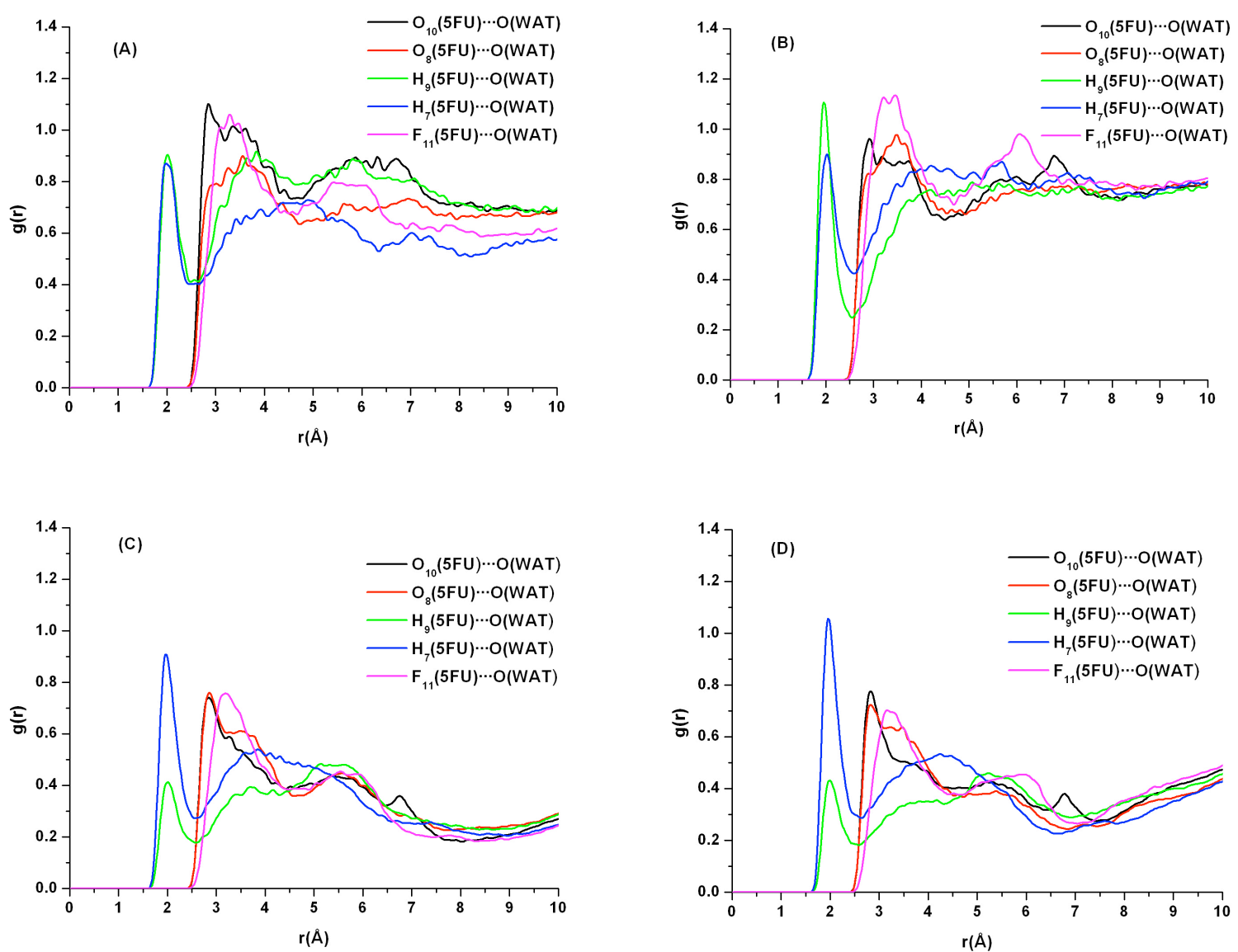

Figure 5: Radial distribution functions for the different atoms of 5FU with the water $\mathrm{O}$ atom in the WL $(\mathrm{A}, \mathrm{C})$ and QAEA (B, D) systems. A and B correspond to densities in bulk water; $\mathrm{C}$ and $\mathrm{D}$ to those in the transport pathway. 

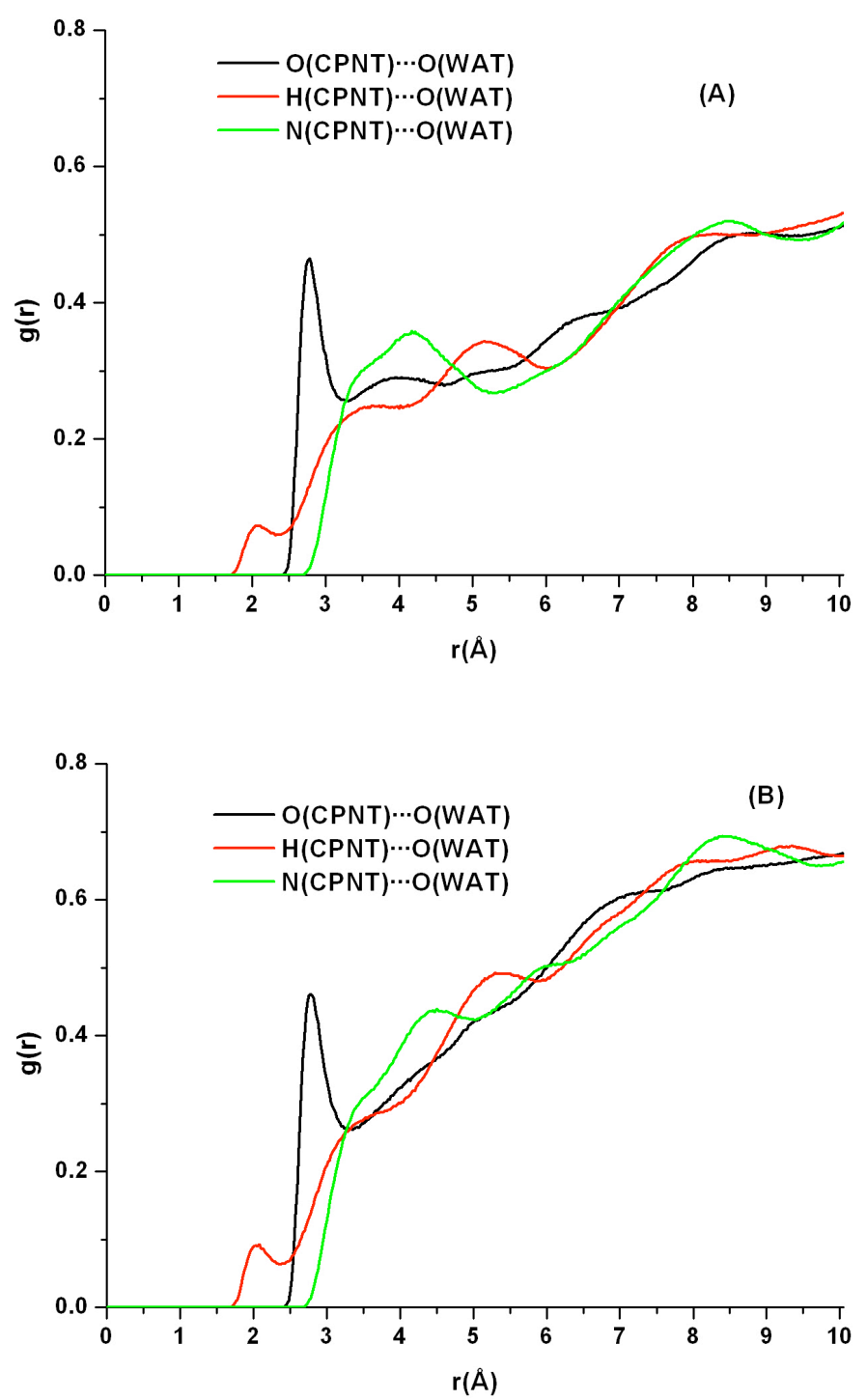

Figure 6: Radial distribution function for carbonyl-amide groups of CPNT with water O atom of the (A) WL and (B) QAEA systems. 
(A)

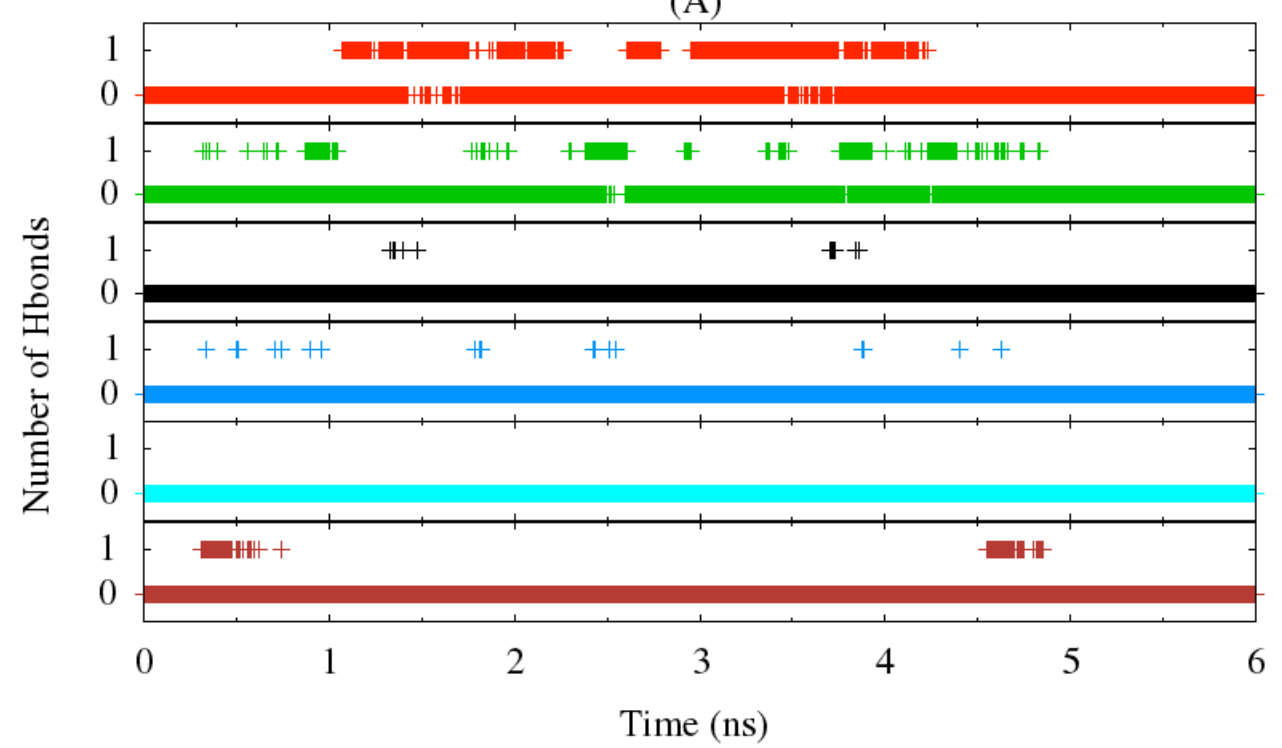

(B)

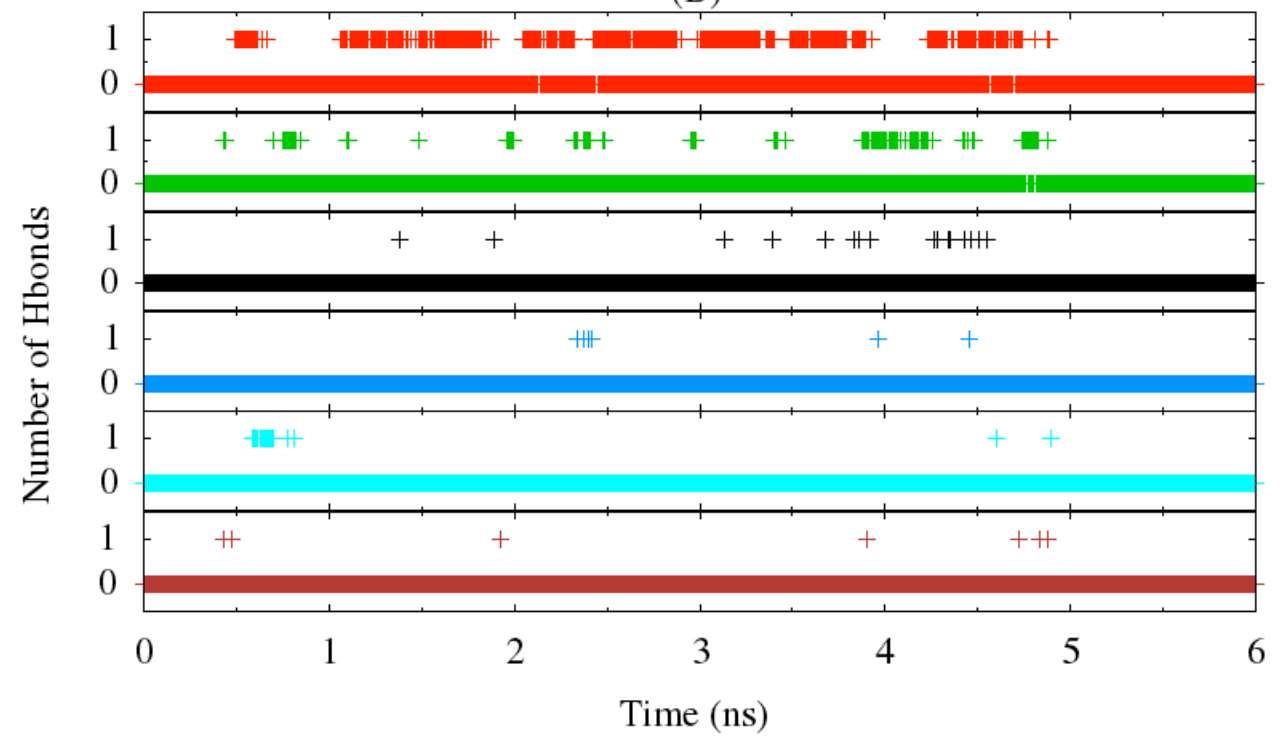

Figure 7: Number of H-bonds between CPNT carbonyl-amide functionality with different atoms of 5FU in the (A) WL and (B) QAEA systems from SMD simulation. H-bonds: $\mathrm{O}(\mathrm{CPNT}){ }^{\cdots} \mathrm{N}_{3} \mathrm{H}_{9}(5 \mathrm{FU}) \quad($ red $), \quad \mathrm{O}(\mathrm{CPNT}){ }^{\cdots} \mathrm{N}_{1} \mathrm{H}_{7}(5 \mathrm{FU}) \quad$ (green), $\quad \mathrm{N}(\mathrm{CPNT}) \cdots \mathrm{N}_{3} \mathrm{H}_{9}(5 \mathrm{FU})$ (black), $\quad \mathrm{N}(\mathrm{CPNT}) \cdots \mathrm{N}_{1} \mathrm{H}_{7}(5 \mathrm{FU}) \quad$ (blue), $\quad \mathrm{NH}(\mathrm{CPNT}) \cdots \mathrm{O}_{10}(5 \mathrm{FU}) \quad$ (cyan), $\mathrm{NH}(\mathrm{CPNT}) \cdots \mathrm{O}_{8}(5 \mathrm{FU})$ (brown). 


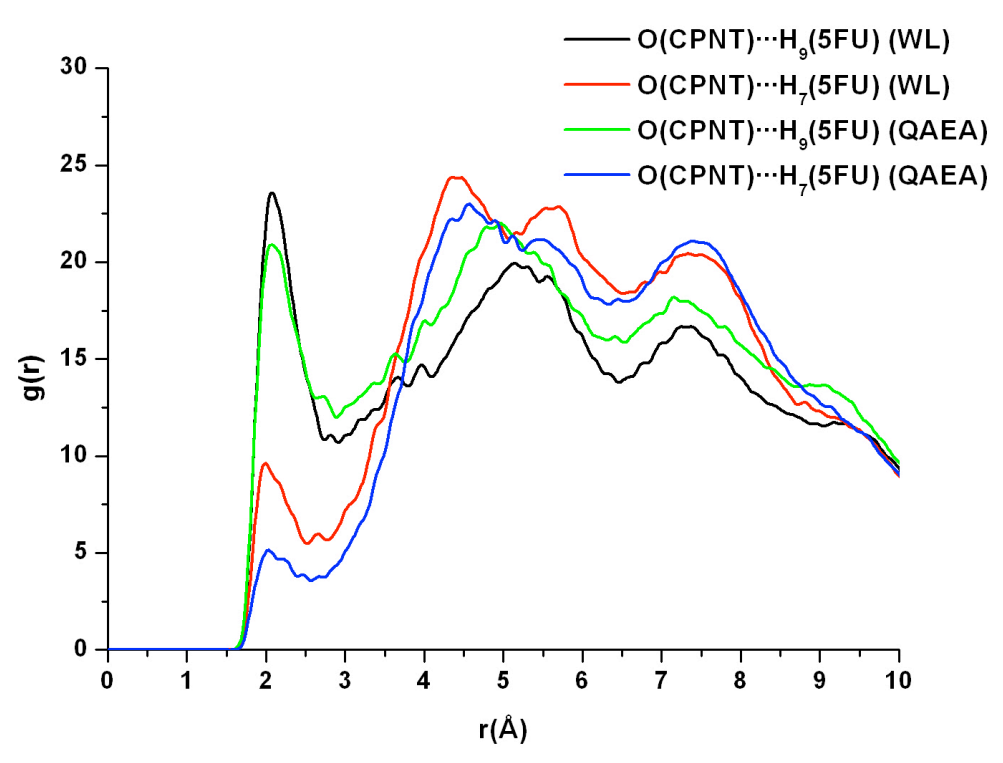

Figure 8: Radial distribution function between the carbonyl $\mathrm{O}(\mathrm{CPNT})$ and $5 \mathrm{FU}$ in the WL and QAEA systems.
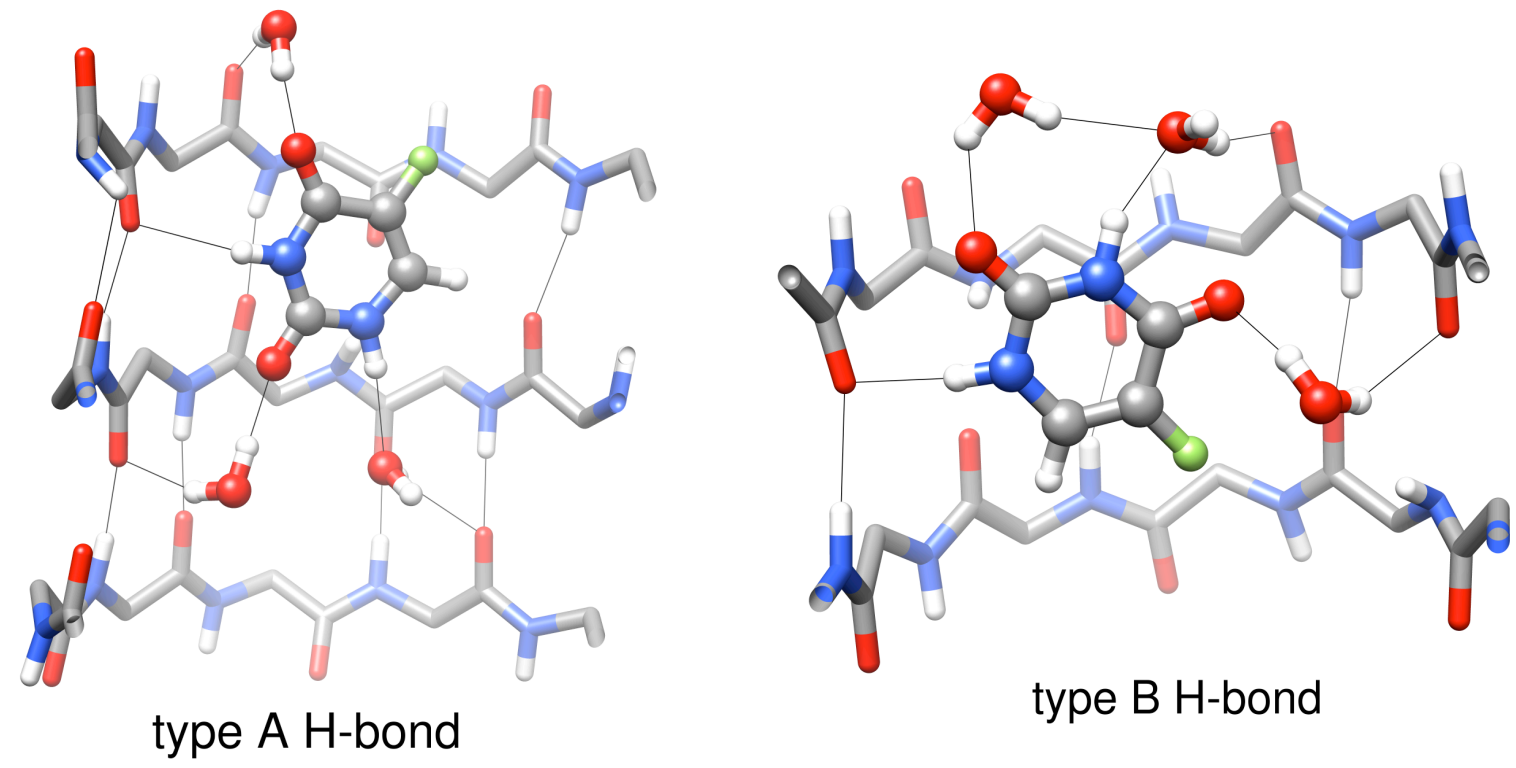

Figure 9: Truncated model structures of WL system showing different H-bonding interactions between the CPNT and 5FU. The intermolecular H-bonds are shown with black lines. 

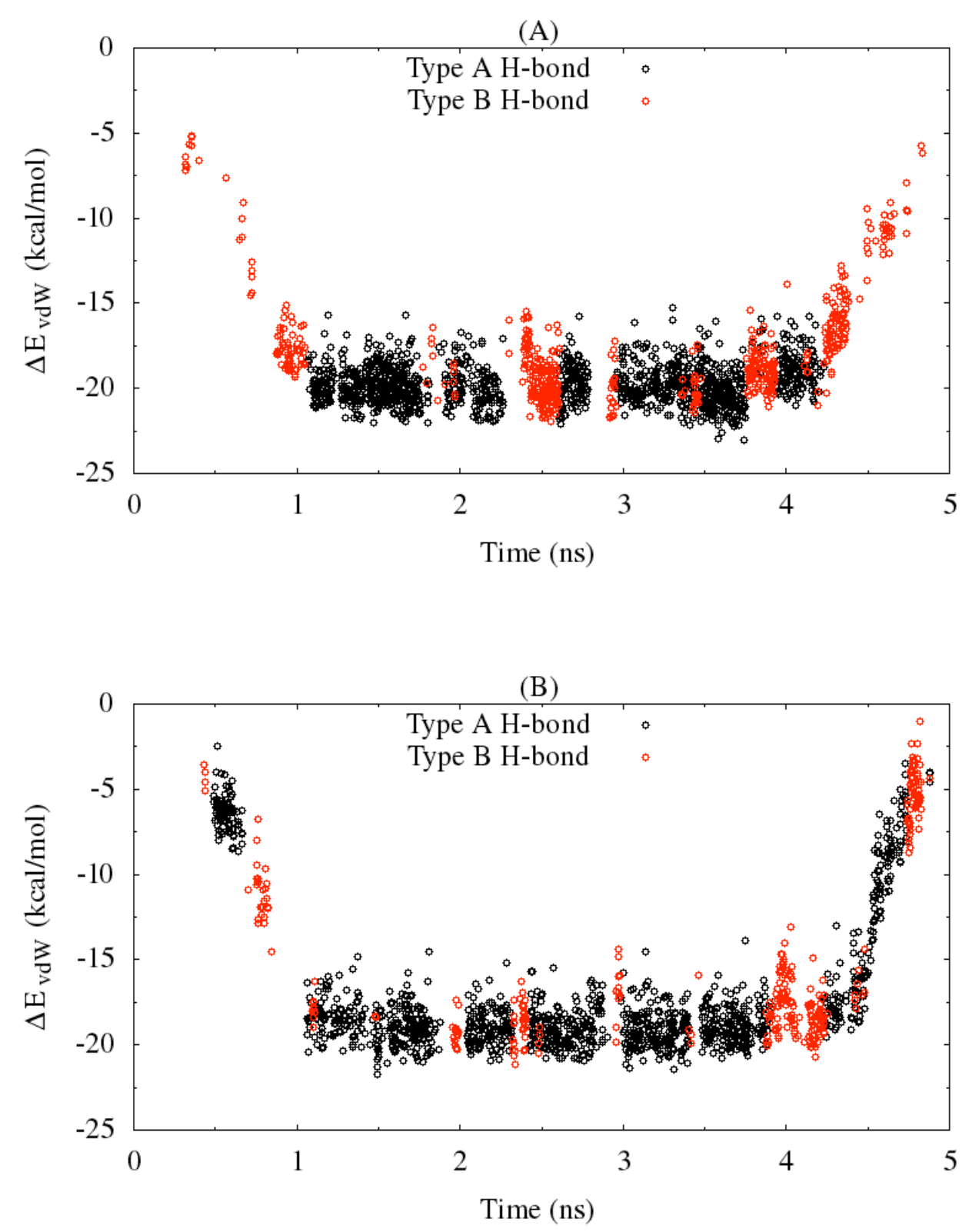

Figure 10: The calculated van der Waals energy contribution to the free energy of binding of CPNT-5FU complexes of the (A) WL and (B) QAEA systems. 
(A)

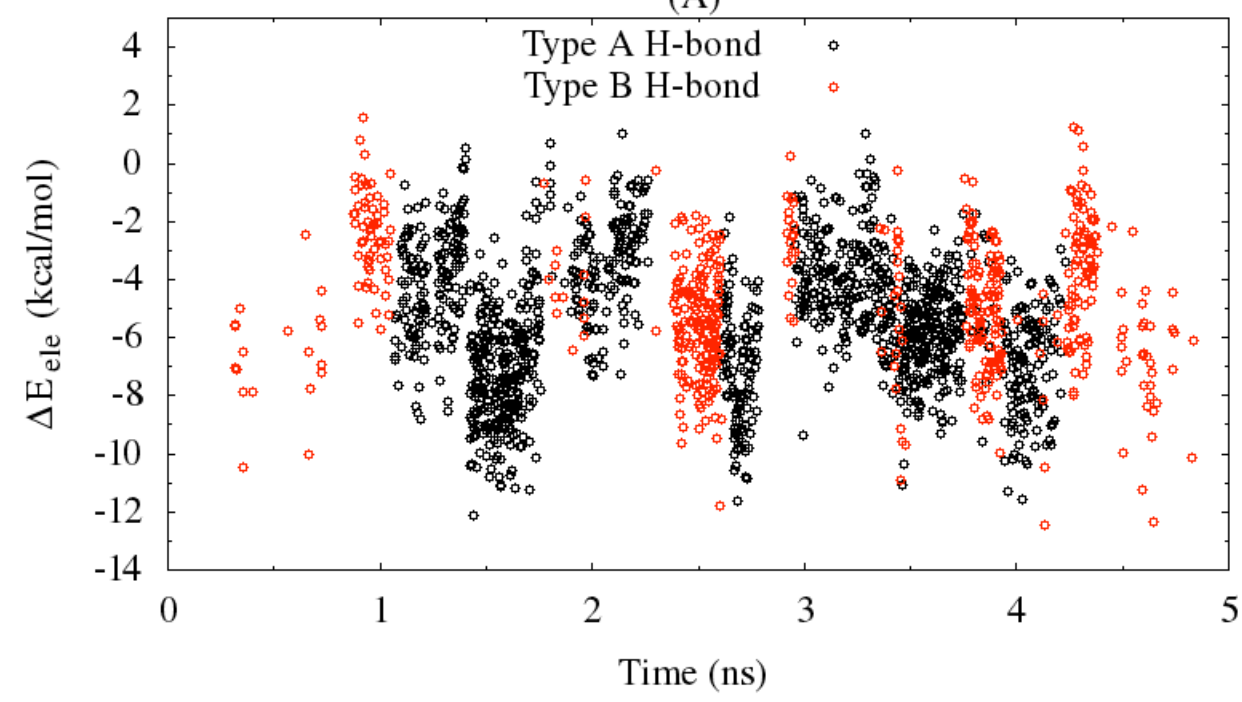

(B)

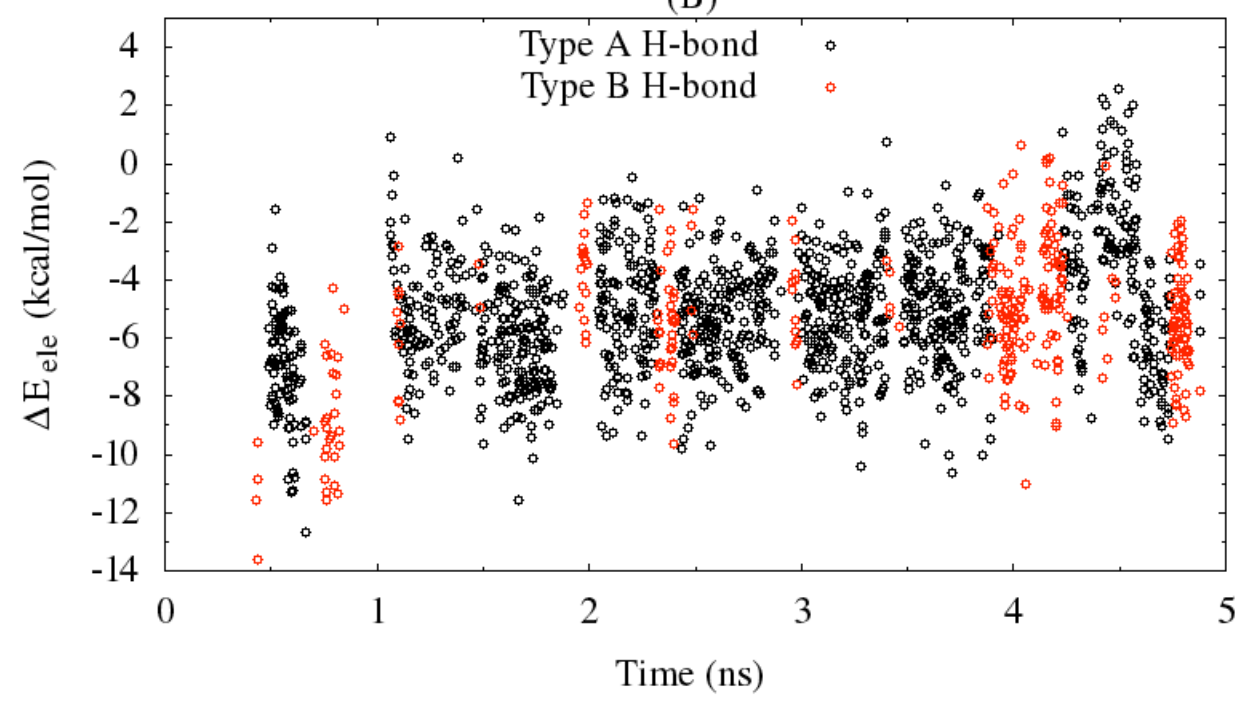

Figure 11: The calculated electrostatic energy contribution to the free energy of binding of type A and B H-bonded CPNT-5FU complexes of the (A) WL and (B) QAEA systems. 

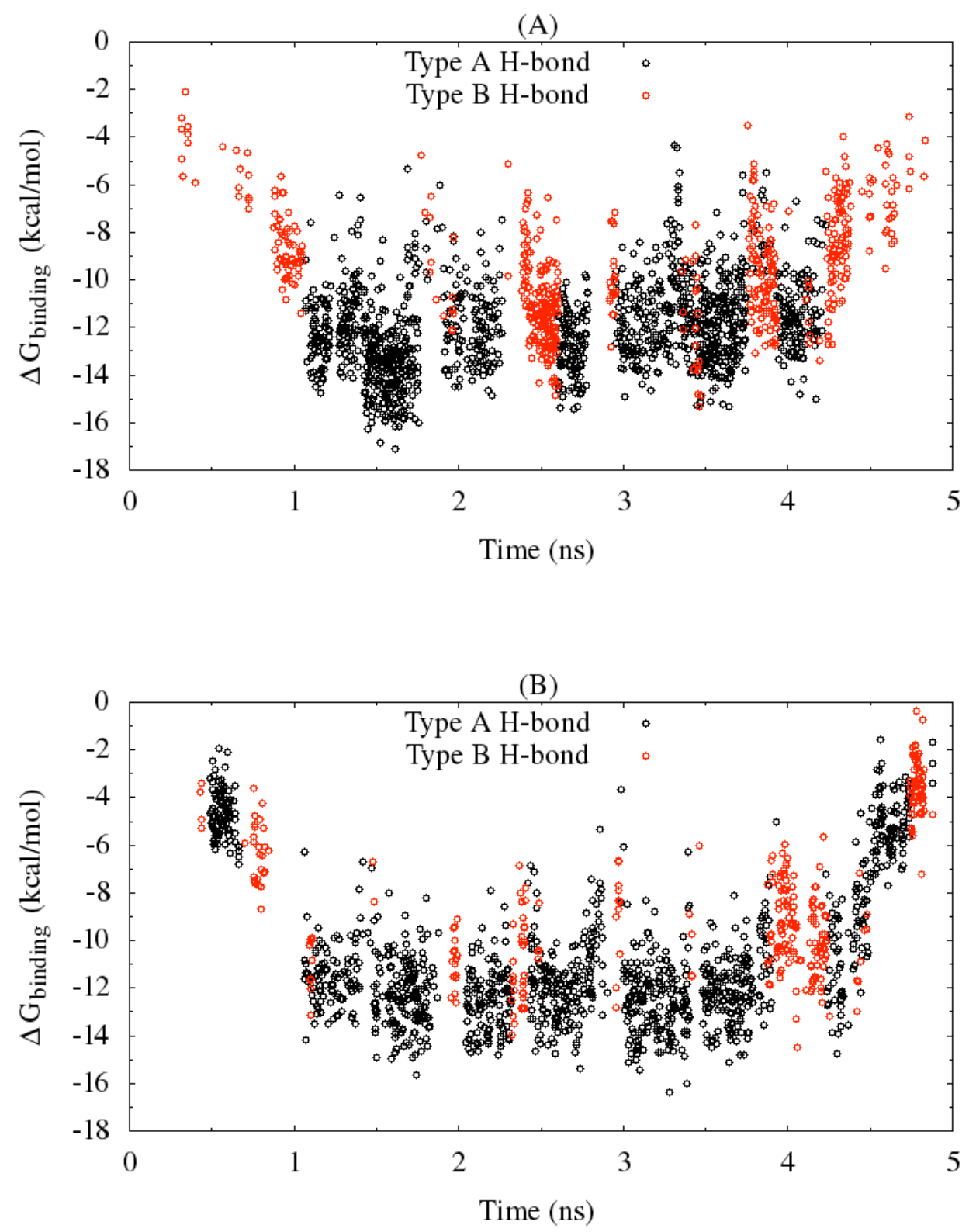

Figure 12: The free energy of binding of type A and B H-bonded CPNT-5FU complexes of the (A) WL and (B) QAEA systems. 


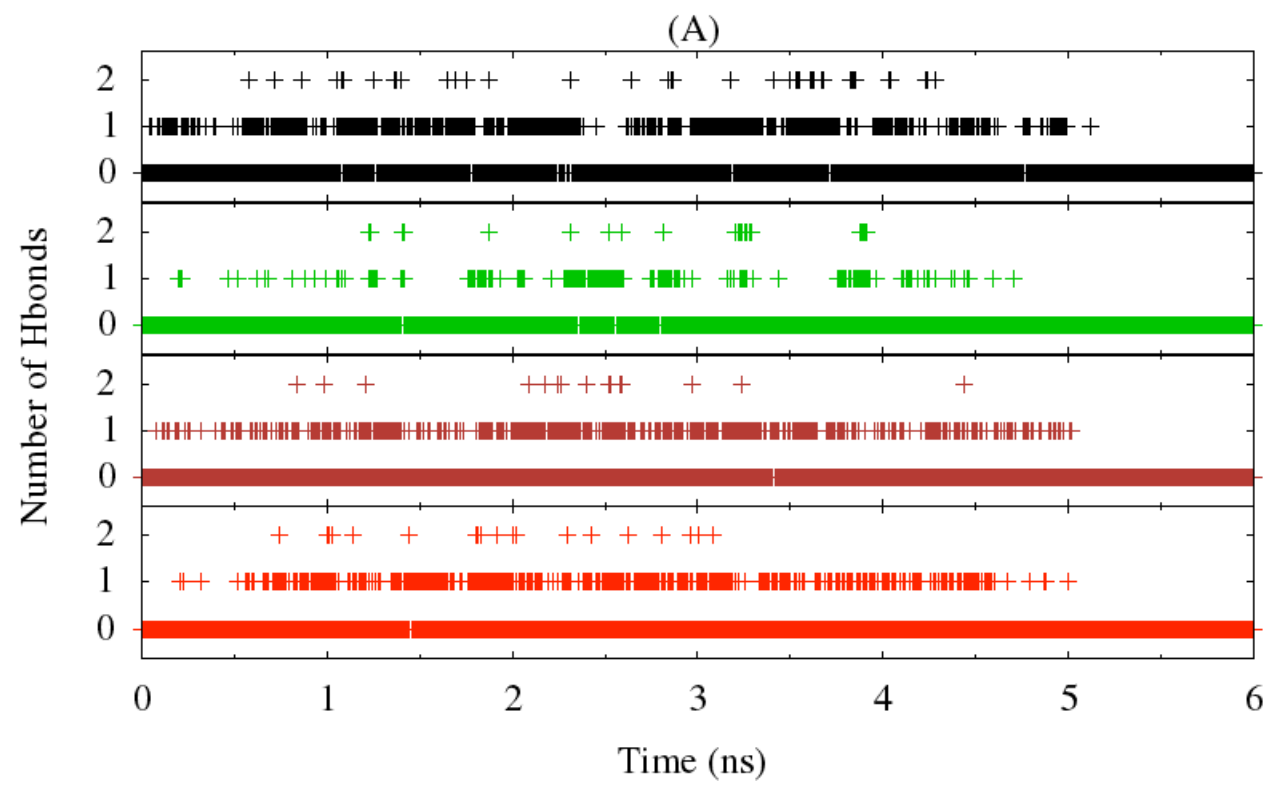

(B)

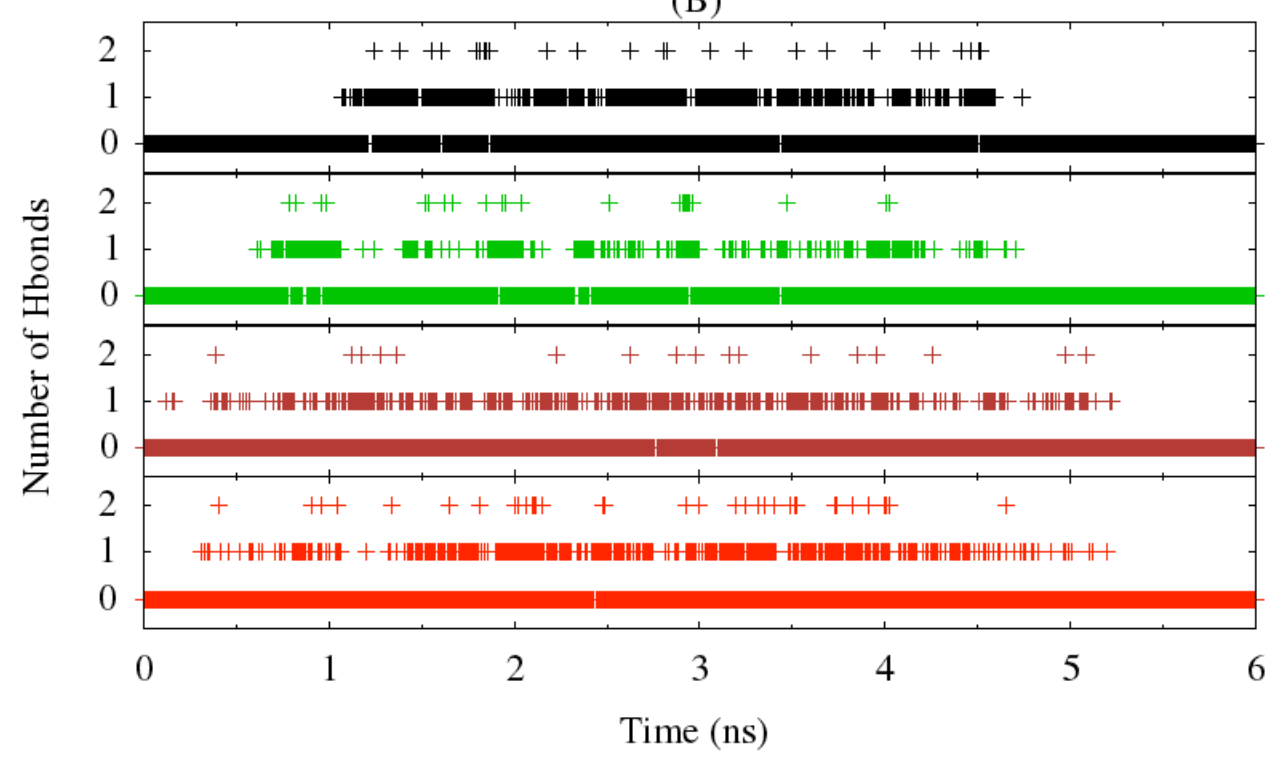

Figure 13: Water mediated $\mathrm{H}-$ bonds between carbonyl $\mathrm{O}(\mathrm{CPNT})$ and various atoms of 5FU observed for the (A) WL and (B) QAEA systems. H-bonds: $\mathrm{O}(\mathrm{CPNT}){ }^{\cdots} \mathrm{H}-\mathrm{O}$ $(\mathrm{WAT}){ }^{\cdots} \mathrm{N}_{1} \mathrm{H}_{7}(5 \mathrm{FU})$ (black), O(CPNT) ${ }^{\cdots} \mathrm{H}-\mathrm{O}(\mathrm{WAT}){ }^{\cdots} \mathrm{N}_{3} \mathrm{H}_{9}(5 \mathrm{FU})$ (Green), O(CPNT) ${ }^{\cdots} \mathrm{H}-$ $\mathrm{O}-\mathrm{H}(\mathrm{WAT}){ }^{\cdots} \mathrm{O}_{8}(5 \mathrm{FU})$ (Brown), $\mathrm{O}(\mathrm{CPNT}){ }^{\cdots} \mathrm{H}-\mathrm{O}-\mathrm{H}(\mathrm{WAT}){ }^{\cdots} \mathrm{O}_{10}(5 \mathrm{FU})(\mathrm{Red})$. 


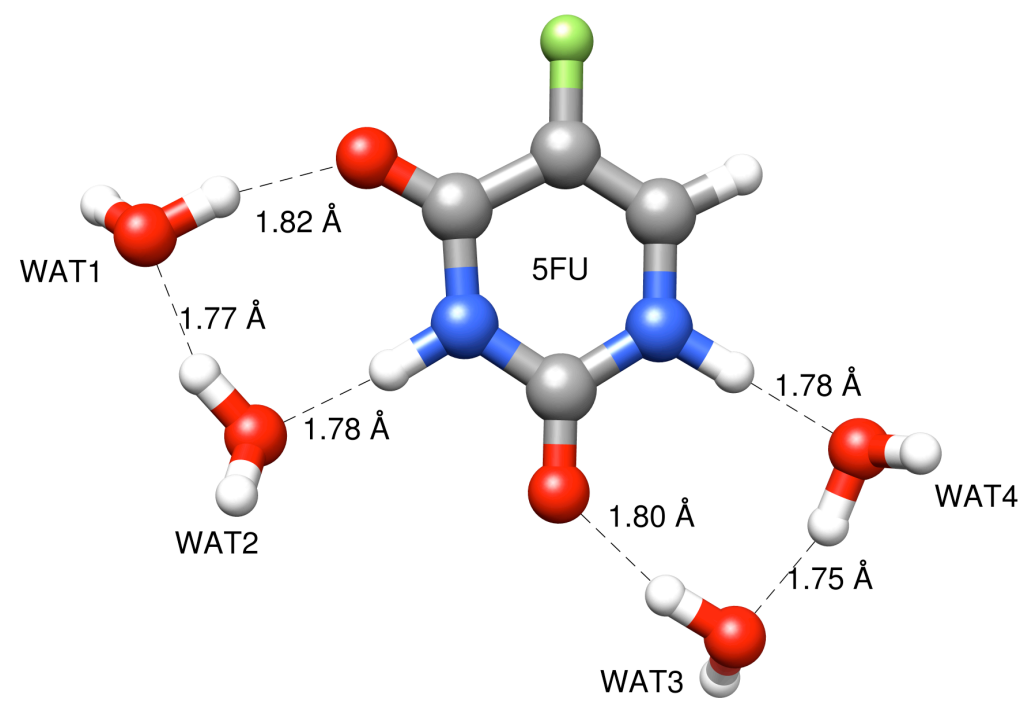

Figure 14: The optimized geometry of the 5FU-water complex. 


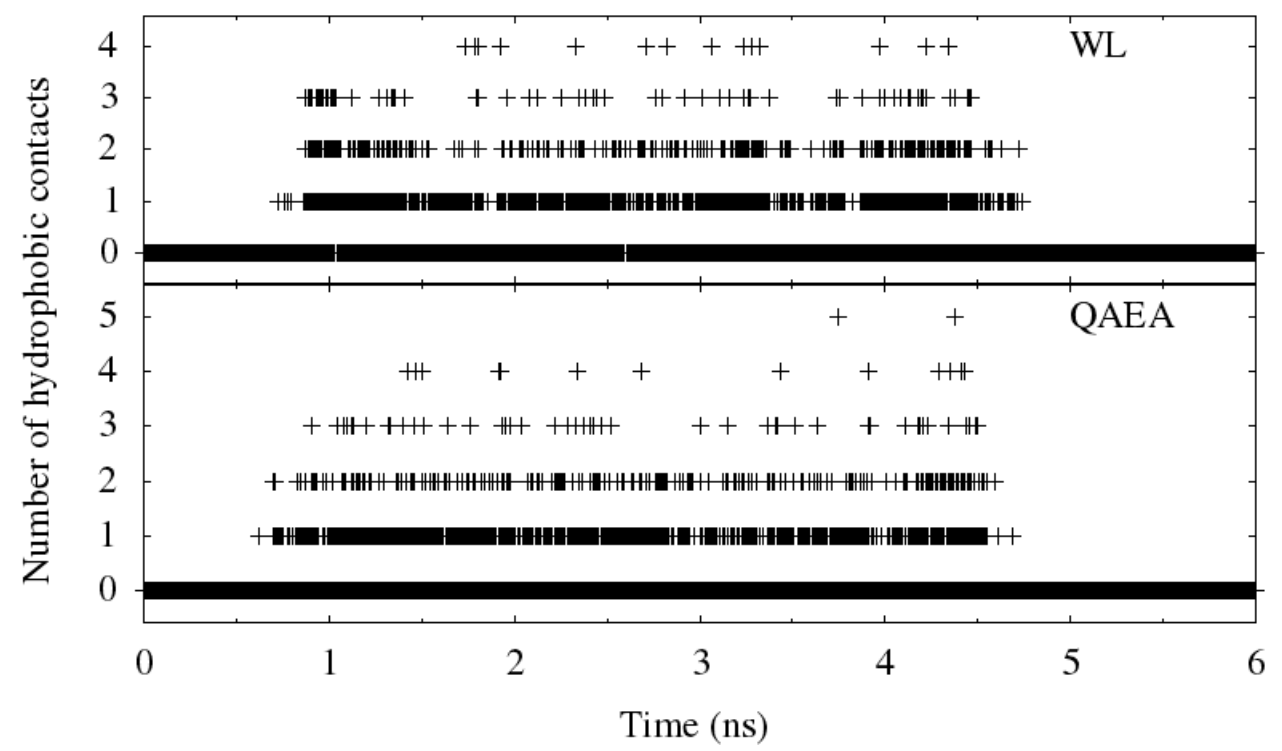

Figure 15: Number of hydrophobic contacts observed between $5 \mathrm{FU}\left(\mathrm{C}_{2}, \mathrm{C}_{4}, \mathrm{C}_{5}, \mathrm{C}_{6}\right)$ and backbone atoms of the CPNT $(\mathrm{C} \alpha, \mathrm{C})$ for the (A) WL and (B) QAEA systems from SMD simulations.

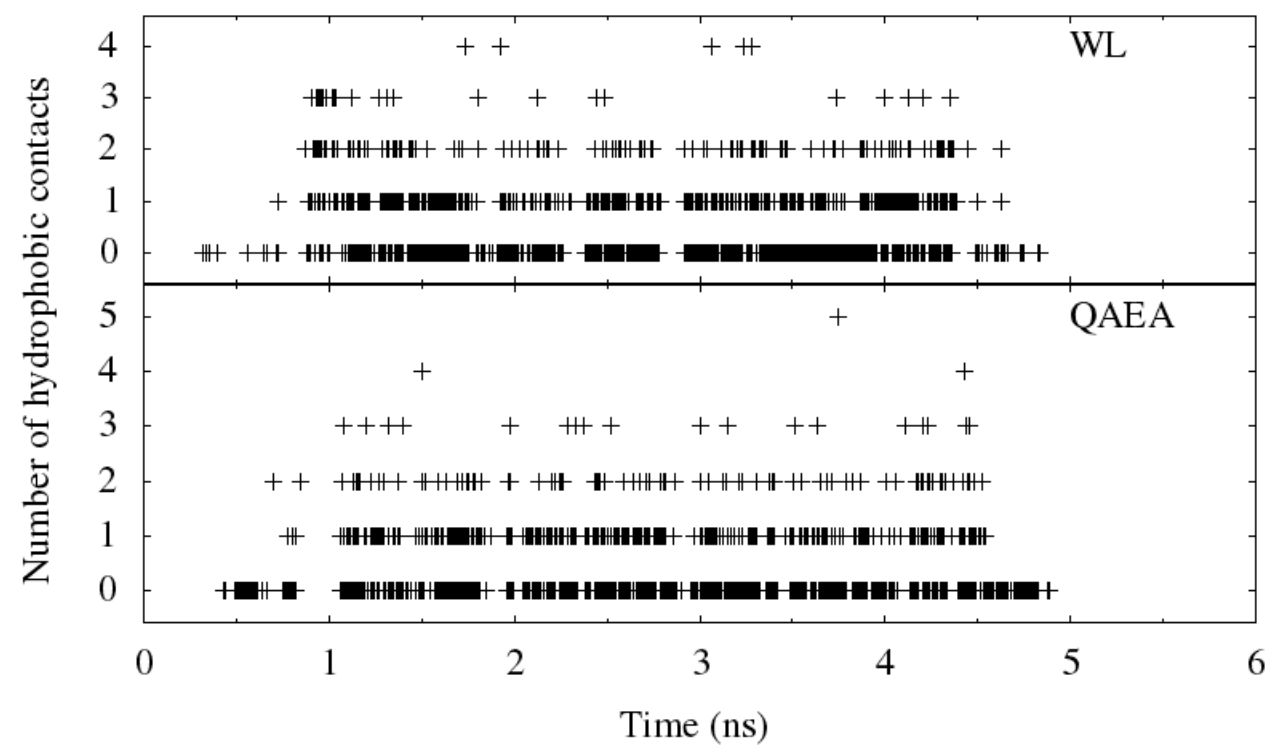

Figure 16: Coexistence of hydrophobic contacts between CPNT and 5FU with $\mathrm{O}(\mathrm{CPNT}){ }^{\cdots} \mathrm{N}_{1} \mathrm{H}_{7} / \mathrm{N}_{3} \mathrm{H}_{9}(5 \mathrm{FU}) \mathrm{H}$-bonds. 


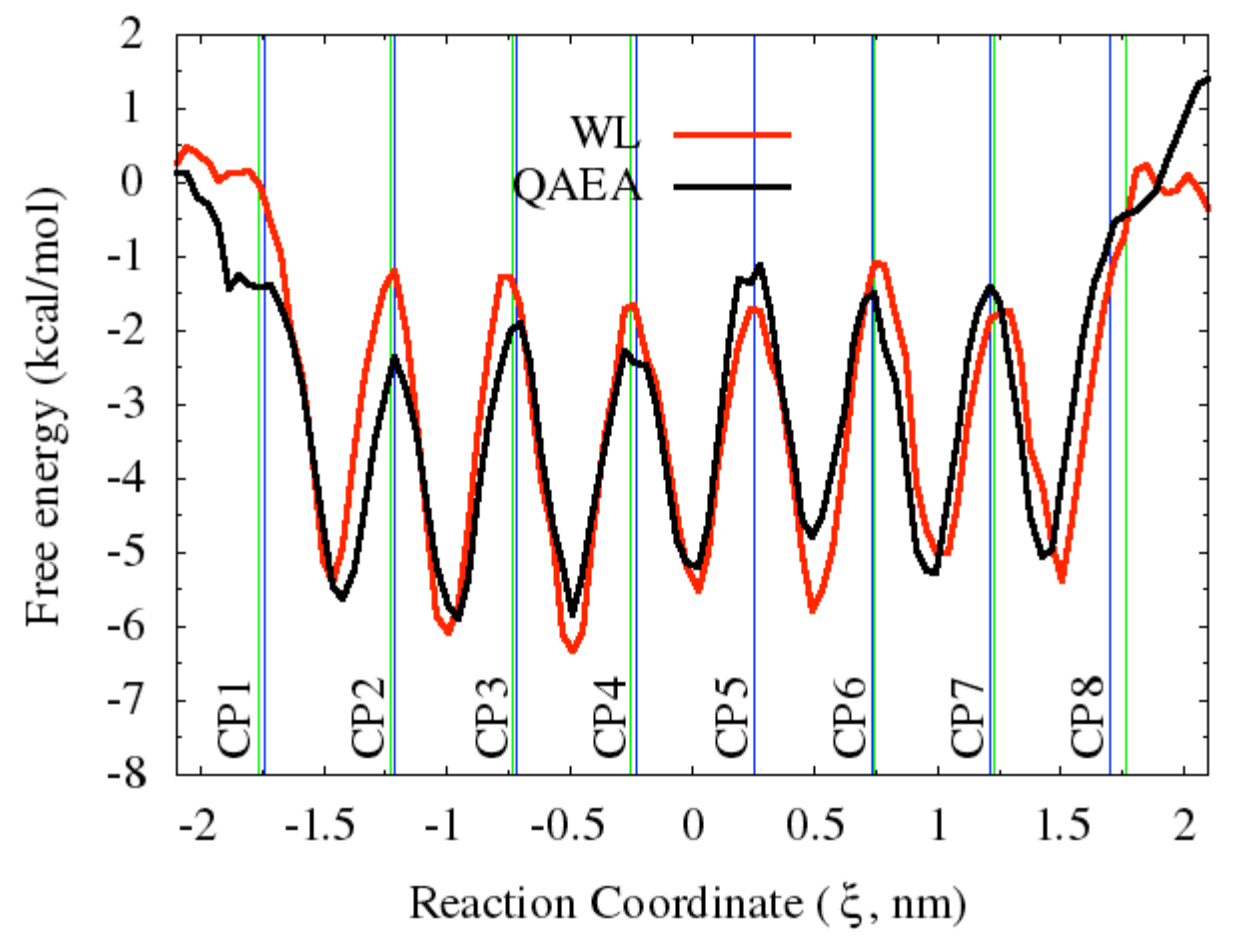

Figure 17: Free energy profile for the transport of 5FU through various CPNTs. The vertical green (WL) and blue (QAEA) lines represent the mean position of the $\mathrm{C} \alpha$ plane region in different CP units. 
Table of Contents (TOC) graphics.

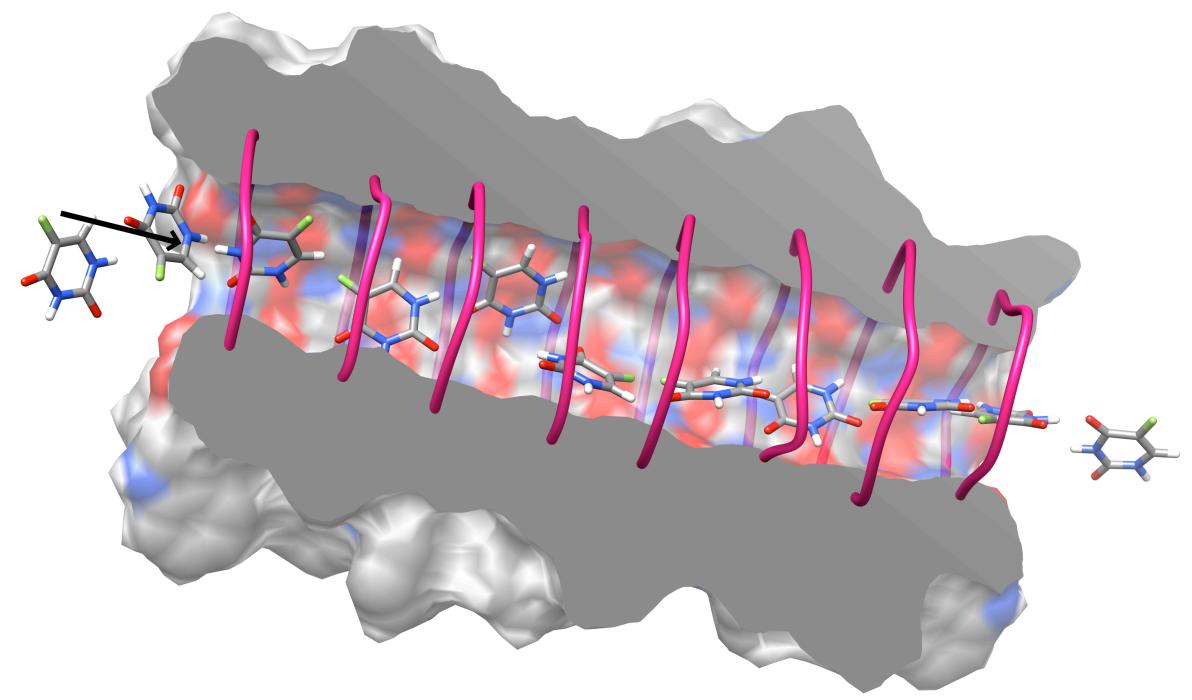

Steered molecular dynamics combined with umbrella sampling simulations have been carried out to unravel the transport mechanism of the 5-Fluorouracil molecule through a cyclic peptide based nanotube. 